Article publié par le Laboratoire de Construction en Béton de l'EPFL

\begin{tabular}{|l|l|}
\hline Title: & $\begin{array}{l}\text { Shear failures in reinforced concrete members without transverse reinforcement: } \\
\text { An analysis of the critical shear crack development on the basis of test results }\end{array}$ \\
\hline Authors: & Cavagnis F., Fernández Ruiz M., Muttoni A. \\
\hline Published in: & Engineering structures \\
\hline DOI & $10.1016 /$ j.engstruct.2015.09.015 \\
\hline $\begin{array}{l}\text { Volume: } \\
\text { Pages: }\end{array}$ & $\begin{array}{l}\text { Vol. } 103 \\
\text { pp. } 157-173\end{array}$ \\
\hline Country: & UK \\
\hline Year of publication: & 2015 \\
\hline Type of publication: & Peer reviewed journal article \\
\hline
\end{tabular}

Please quote as:

Cavagnis F., Fernández Ruiz M., Muttoni A., Shear failures in reinforced concrete members without transverse reinforcement: An analysis of the critical shear crack development on the basis of test results, Engineering structures, Vol. 103, UK, 2015, pp. 157-173. 


\title{
Shear failures in reinforced concrete members without transverse reinforcement: An analysis of the critical shear crack development on the basis of test results
}

\author{
Francesco Cavagnis, Miguel Fernández Ruiz*, Aurelio Muttoni \\ École Polytechnique Fédérale de Lausanne, Station 18, CH-1015 Lausanne, Switzerland
}

\section{A R T I C L E I N F O}

\section{Article history:}

Received 28 April 2015

Revised 24 August 2015

Accepted 8 September 2015

\section{Keywords:}

Shear

Concrete structures

Experimental observations

Photogrammetry

\begin{abstract}
A B S T R A C T
Shear in concrete members without transverse reinforcement can be carried by various potential sheartransfer actions, whose activation depends much on the actual cracking pattern and kinematics at failure. Failures can occur in a progressive manner (at the end of a stable propagation of a critical shear crack) or in a sudden manner (by an unstable progression or development of a new crack). In addition, the development and shape of the failure crack may also be very different from case to case. These differences influence which shear-transfer actions may be governing for a given member and loading situation. Despite the large number of specimens tested in shear, almost no information on the actual crack development during the process of failure is yet available. This paper presents the results of an experimental programme consisting of thirteen beams. The tests were designed to investigate different structural systems and loading conditions commonly found in practice (cantilevers with concentrated and distributed loading, single span beams with distributed loading and continuous beams). The cracking patterns and their associated kinematics were tracked in detail by using photogrammetric techniques at high frequencies during testing and particularly during the process of failure, providing data on the actual crack development leading to shear failure. The observations show that very different cracking patterns may be found and that they might be also developed in different manners. The results are interpreted with reference to the measured crack kinematics and related to the various potential shear-transfer actions, with the aim of providing a useful material towards the development of rational approaches for shear design.
\end{abstract}

(C) 2015 Elsevier Ltd. All rights reserved.

\section{Introduction}

Shear design has attracted significant research efforts since the first constructions in reinforced concrete. Particularly, in the case of members without transverse reinforcement, shear is acknowledged as a failure mode potentially governing the design at ultimate limit state and being particularly critical due to its limited capacity of deformation and brittleness. Contrary to design of beams with transverse reinforcement, where consistent design methods based on equilibrium solutions were early developed [1-4], shear design of one-way slabs and beams without transverse reinforcement has mainly remained based on empirical equations in many codes of practice $[5,6]$.

Despite the lack of a generally-accepted mechanical approach, significant research efforts have been devoted in the last decades on the phenomenon of shear-transfer in reinforced concrete

\footnotetext{
* Corresponding author.

E-mail address: miguel.fernandezruiz@epfl.ch (M. Fernández Ruiz).
}

[7-11,13-15]. These investigations have allowed understanding the basic shear-transfer actions in reinforced concrete members and have led to the development of mechanical models for shear design. These models have reached a certain level of maturity and are starting to be incorporated into design codes [16-18]. Nevertheless, it is interesting to observe that despite the fact that the different mechanical models predict similar shear strengths, they are not necessarily in agreement on the governing sheartransfer action carrying the load (or their relative significance). A potential reason for this disagreement is grounded on the fact that the mechanical models are usually based on the interpretation of a crack pattern after failure or based on a measured kinematics before it happens. This is the consequence of conventional measurement techniques, that in many cases have not been capable of tracking the crack development during the process of failure. Thus, most times, the interpretation of the shear-transfer actions is performed on the basis of pictures taken prior failure or after it. This might nevertheless have consequences unless the analysis is performed on the basis of a picture taken right at failure 
(maximum load), as redistributions amongst the potential sheartransfer actions develop before or during the process of failure (sometimes allowing the member to withstand the applied actions in a stable manner, but sometimes not). In addition, the analysis of the kinematics and cracking pattern during the process of failure yields to a better understanding of the activation of the various shear-transfer actions and failure modes.

In this situation, new measurements techniques are providing a significant breakthrough to obtain better interpretation of the experimental evidence [19]. In particular, digital measurement from high-resolution photography (photogrammetry) constitutes a consistent tool to obtain accurate measurements of strains and crack widths at high frequencies (even higher than $1 \mathrm{~Hz}$ ). The use of this tool enables detailed investigation of the instants preceding the maximum load and right after it, allowing interpretation of the process during which failure occurs.

In this paper, the results of an experimental testing programme are presented. Other than conventional measurements, photogrammetric techniques were implemented and processed, allowing detailed observations of the actual mechanisms leading to failure. These results are thoroughly explained and related to the sheartransfer actions. It is observed that causes leading to failure are not necessarily the same for the tested members, partly justifying the points of view of different (even contradictory) approaches for mechanical modelling of shear. The experimental programme also investigates the differences that are found between classical laboratory testing (single span beams subjected to concentrated loads) with respect to conditions representative of actual members (continuous beams, distributed loading, compression reinforcement). On the basis of these observations, a critical review of the sheartransfer actions and their role is presented, as well as the agreement and disagreement with some selected mechanical models.

\section{Classical definitions of shear-transfer actions and mechanical modelling in reinforced concrete members}

The development of mechanical models in reinforced concrete beams without stirrups has been normally performed by accounting for the equilibrium of inner forces developing at a free-body (Fig. 1a) or by considering the role of the potential shear-transfer actions (Fig. 1b-f). Both approaches are in fact related to the principles of the upper- and lower-bound theorems of the theory of plasticity [20]. The former (forces acting on a free-body) investigates on the actions at the edges of the free-body related to the failure mechanism (without any further check inside the freebodies). The latter usually considers one or more shear-transfer actions as potentially governing, whose maximum strength is calculated on the basis of a licit stress field.

Developing a suitable approach should in fact incorporate both perspectives, accounting both for a suitable stress field and a compatible kinematics allowing activation of the shear-transfer actions. Conventionally, the shear-transfer actions are classified into beam shear-transfer actions (Fig. 1c-f) and the arching action (Fig. 1b). Beam shear-transfer actions require development of tensile stresses in concrete, and allow for the force in the tension chord to vary. They are usually referred as cantilever action (Fig. 1c), residual tensile strength action (Fig. 1d), dowel action (Fig. 1e) and aggregate interlock (Fig. 1f). With respect to full arching action (Fig. 1b), no tensile strength is required in the concrete and the force in the reinforcement remains constant (according to limit analysis, all shear force can be carried without transverse reinforcement by an inclined direct strut [21]). In reality, arching action can also happen combined with the beam shear-transfer actions (Fig. 1f). With respect to the beam shear-transfer actions:

- Cantilever action (Fig. 1c) was acknowledged by Kani as a basic action for shear-transfer [10]. It consists on the development of inclined struts and ties in the concrete between two flexural cracks (Fig. 1c). For a cross-section at the location of a bending crack, shear is carried by the inclination of the compression zone (component $V_{c}$ in Fig. 1a).

- Residual tensile stresses of concrete (Fig. 1d, component $V_{t}$ in Fig. 1a). This action can be considered only significant for low cracks openings (or near the tip of the crack).

- Dowelling action (Fig. 1e) requires developing tensile stresses in the concrete cover potentially leading to its delamination. Even after delamination, dowelling action is still possible $[11,24]$ (component $V_{d}$ in Fig. 1a). In members with compression reinforcement, significant dowelling action can develop provided that the reinforcement is intercepted by the failure crack [24].

- Aggregate interlock (Fig. 1f) allows developing shear and compressive stresses through the cracks due to the roughness of cracked concrete $[14,22,23]$ (component $V_{a}$ in Fig. 1a). It is an efficient shear-transfer action, yet quite sensitive to the opening of the cracks.

Most of the available design models for shear usually acknowledge one of the previous shear-carrying actions as governing. For instance, the Modified Compression Field Theory [12], can be considered as a theory accounting primarily for the role of aggregate interlock in case of members without transverse reinforcement. The role of the inclination of the compression chord (a)

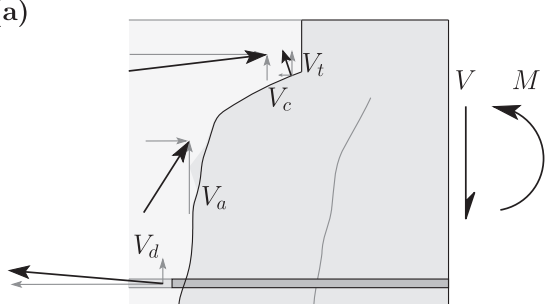

(b)

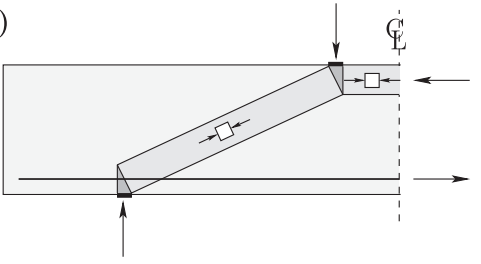

(c)

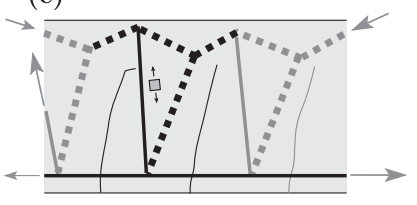

(e)

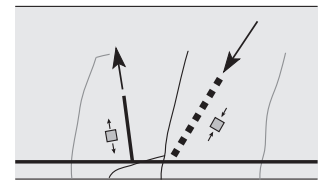

(d)
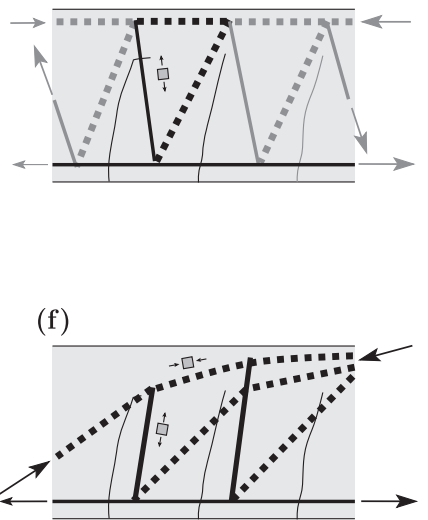

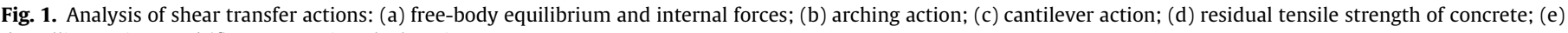
dowelling action; and (f) aggregate interlock action. 
(combined cantilever and arching action) is referred by Zararis [25], and Tureyen and Frosch [26]. The role of delamination and its influence in failures controlled by aggregate interlock has been recently explored by Yang [27]. There are also some approaches considering plasticity [28] and even modifying dissipation along the yield lines depending on the cracking state [29].

Other models for shear design, nevertheless, acknowledge also contribution of other actions and even allow calculating the contribution of each. A physical approach considering the contribution of all potential shear-transfer actions has recently been developed by Marí et al. [30] and also by Tue et al. [31]. The Critical Shear Crack Theory [32] has also acknowledged the role of the various sheartransfer actions, with cracking as an estimator of the decrease of the total shear strength.

\section{Testing programme and refined measurements on kinematics at failure}

In the following, the results of an experimental programme consisting of 13 beams (Figs. 2 and 3) tested at Ecole Polytechnique Fédérale de Lausanne (Switzerland) will be presented. The tests were performed with the aim of obtaining refined measurements on the crack development and kinematics during the process of failure. A total of 15 tests were performed on 13 specimens, as two of the specimens could be strengthened after failure on one side and then were reloaded until failure occurred on the other side (specimens SC51 and SC52). Some specimens were subjected to distributed loading whereas others were subjected to concentrated loads allowing for comparisons on their behaviour (completing a previous work of the authors and Pérez Caldentey et al. [33] on the shear capacity of cantilevers subjected to distributed - uniform or not - loading patterns). The present series was designed to investigate different structural systems and loading conditions commonly found in practice (cantilevers with concentrated and distributed loading, single span beams with distributed loading and continuous beams).

\subsection{Geometry}

The specimens were rectangular beams of constant width $(250 \mathrm{~mm})$ and depth $(600 \mathrm{~mm})$, Fig. 2. Two amounts of flexural reinforcement ratio were used, corresponding to $\rho=0.54 \%$ ( 2 bars diameter $22 \mathrm{~mm}$, effective flexural depth $d=559 \mathrm{~mm}$,) and $0.89 \%$ ( 2 bars diameter $28 \mathrm{~mm}$, effective flexural depth $d=556 \mathrm{~mm}$ ). The same bars placed on the tension side were also arranged in the compression side (for casting, the top bars were hang from an external steel profile in order to keep a constant concrete cover). This was aimed at allowing the beams to be capable of bearing both positive and negative bending moments accounting for the test setup and to reproduce a situation commonly found in practice.

The specimens have variable length in order to investigate on the influence of shear slenderness. The beams were tested as cantilevers, single span or continuous members under various loading conditions. For two-span members, only one span was investigated, whereas in the other shear failures were avoided by arranging stirrups (diameter 10 spaced at $100 \mathrm{~mm}$ ), refer to Fig. 2. The loads were introduced by means of $200 \times 150 \mathrm{~mm}$ neoprene pads ( $50 \mathrm{~mm}$ thick) spaced at $175 \mathrm{~mm}$ to simulate distributed loading conditions. At the supports, the reactions were applied by means of $250 \times 200 \mathrm{~mm}$ steel plates with a thickness of $30 \mathrm{~mm}$. The various hydraulic jacks reproducing a distributed load were connected to the same hydraulic system, ensuring same force at each actuator (neglecting differences in friction losses of the system).

\subsection{Materials}

Normal strength concrete with a maximum coarse aggregate size of $16 \mathrm{~mm}$ was used for all specimens. The compressive strength $\left(f_{c}\right)$ at the time of testing ranged between $33.2 \mathrm{MPa}$ and 36.8 MPa (measured in cylinders $150 \mathrm{~mm}$-diameter and 300-mm height). Details on the compressive strength for each specimen are provided in Table 1. For the reinforcement, high-strength steel bars, with an average yield strength of $710 \mathrm{MPa}$ was used (average tensile strength of the steel after strain hardening at $870 \mathrm{MPa}$ ). This reinforcement type was used in order to increase the bending resistance for the relatively moderate flexural reinforcement ratio to avoid flexural failures whenever possible. For the stirrups, ordinary reinforcement was used (with a characteristic yield strength of $500 \mathrm{MPa}$ ).

\subsection{Test setup}

The test setup was designed to allow different loading conditions and shear slenderness. Details on each specimen are provided below and in Table 1 and Fig. 3:

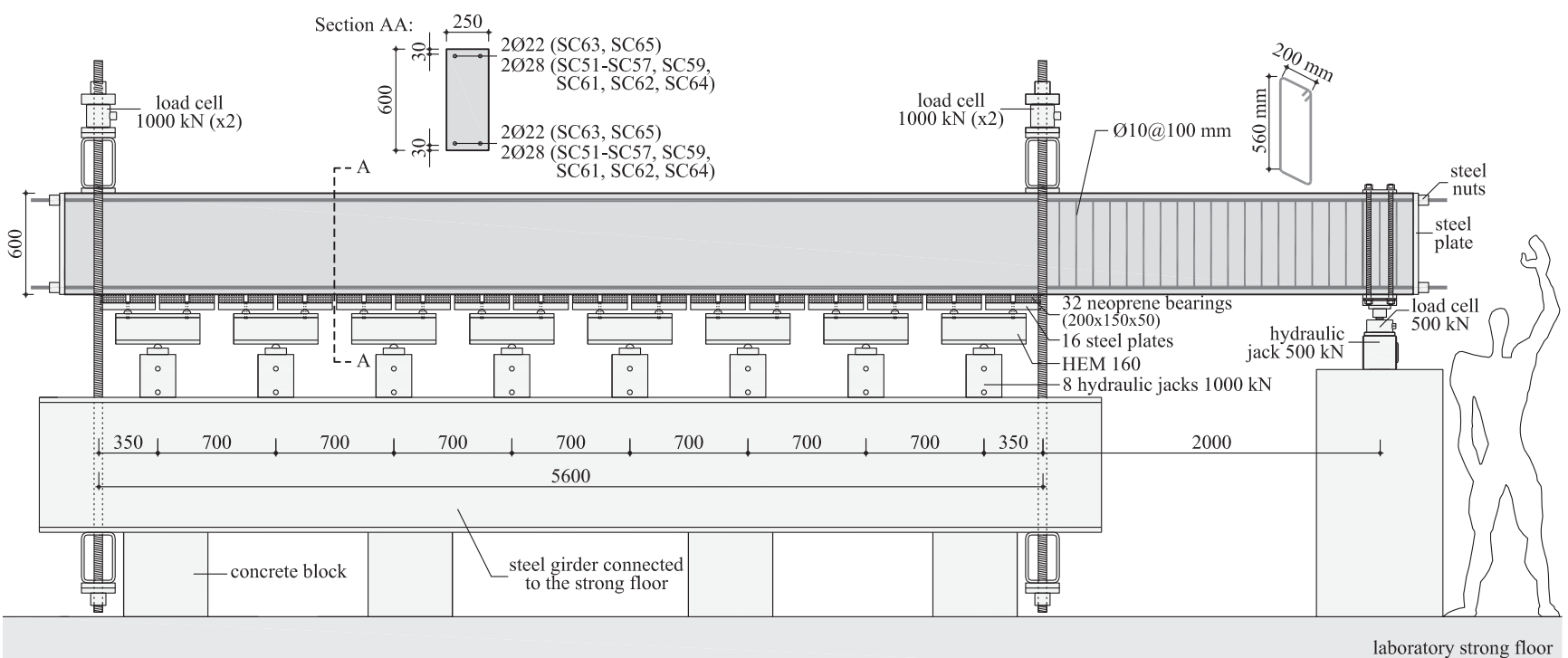

Fig. 2. Test setup (dimensions in $[\mathrm{mm}]$ ). 

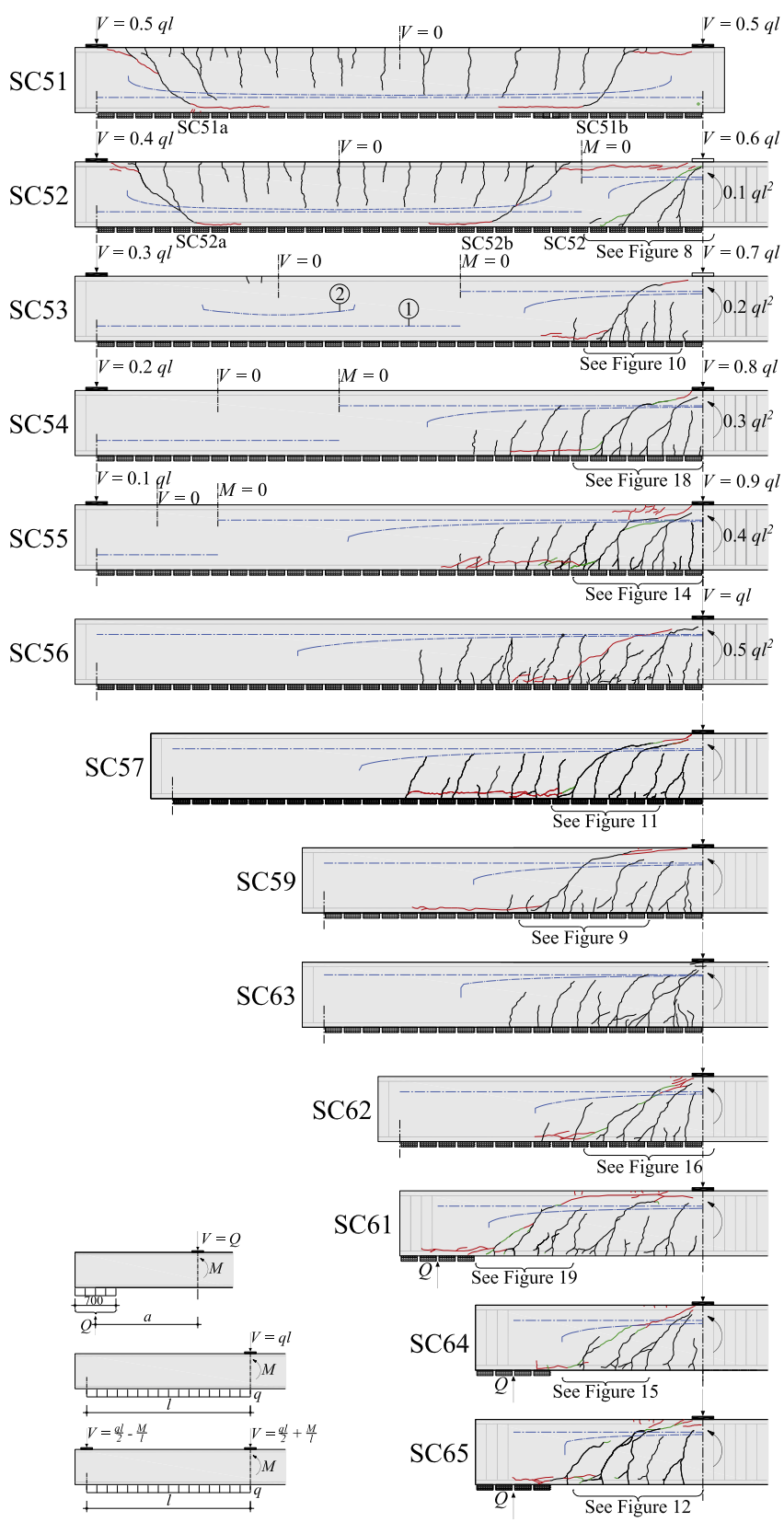

Fig. 3. Testing programme: loading conditions and observed cracking patterns: dashed blue horizontal line (refer to curve (1) in specimen SC53): location of neutral axis according to a bending analysis assuming no tensile strength (calculated according to Appendix B of this paper); curved blue horizontal line (refer to curve (2) in specimen SC53): location of fibre at which the tensile strength is reached (assuming cracked analysis with a maximum tensile strength of concrete equal to $f_{c t}$ ). Cracks in black for increasing load until maximum load; Cracks in green for decreasing load after maximum load (before unstable crack growth); Cracks in red after unstable crack growth leading to failure. (For interpretation of the references to colour in this figure legend, the reader is referred to the web version of this article.)

- Specimen SC51 is a simply supported member subjected to uniformly distributed loading. It was tested twice since it could be repaired after first failure (by means of external plates fixed together with prestressed bolts)

- Specimen SC52-55 are continuous beams subjected to uniform loading and with different negative bending moment (refer to Fig. 3 for details on the point of contraflexure of bending moments and zero shear force). Specimen SC52 could also be tested twice, as it was strengthened after first failure
- Specimen SC56-57, SC59 and SC62-63 are cantilevers subjected to uniformly distributed loading, with varying slenderness except for specimens SC59 and SC63, where the slenderness was the same, but the reinforcement ratio was varied ( $\rho=0.54 \%$ for specimen SC63 and $0.89 \%$ for specimens SC59)

- Specimens SC61 and SC64-65 were tested as cantilevers subjected to a concentrated load at their tip. The concentrated load was applied by means of four neoprene pads for consistency with the load introduction system used for the other specimens. These members were also designed in order to provide equivalent shear slenderness as those of specimens SC57 and SC59-63 respectively. The reinforcement ratio was $0.89 \%$ for all specimens except for SC65, where it was $0.54 \%$

\subsection{Observed cracking patterns}

Cracking patterns were recorded and photographed during loading and until the test were stopped after failure. Pictures were taken normally at $1 \mathrm{~Hz}$ frequency, although for some cases, the frequency was lower $(0.5 \mathrm{~Hz})$ depending on the number of channels where data was acquired. Photogrammetry was performed with two cameras Nikon D800 (36.3 megapixels), whose images were analysed using the VIC3D software [34]. These pictures were also used by digital post-processing of the images to compute the strains at the concrete surface.

A random pattern with small, rounded, not overlapping speckles of constant size was applied on the beam surface. It was generated by using specific software provided by VIC3D for this purpose. The pattern was laser cut into cardboard, glued on the specimen and sprayed in black. Special attention was paid to the influence of the size of the speckles on the measurement accuracy. Depending on the size of the investigated zone, the speckles varied between 3 and 5 pixels and each pixel had a physical dimension of approximately $0.35 \mathrm{~mm}$ (with an upper extreme of $0.6 \mathrm{~mm}$ in the case of large areas of interest). A good calibration allowed obtaining accurate displacement measurements with an error of $1 / 50$ of a pixel.

In addition, LED targets were also glued at the surface of some specimens. The LED targets blink at a selected frequency (about $2 \mathrm{~Hz}$ ) allowing also detailed measurements on the strains of the system. The results of the two techniques (photogrammetry and LED targets) were compared and in general fine agreement was found. Yet, the photogrammetry measurements were found more suitable to provide detailed tracking of the displacement field. They will thus be preferably presented hereafter.

The observed cracking patterns differed much amongst the different specimens (Fig. 3). Yet, a number of typical cracks could be identified due to their shape and origin. The following definitions of crack types will be used later to interpret and to describe the tests (Fig. 4):

- Type A (Fig. 4a): Primary flexural cracks. These cracks have a bending origin. They are early developed and typically present a rather steep slope (yet they are normally inclined in the shear span). The cracks develop normally up to the theoretical location of the fibre where the longitudinal stress reaches the tensile strength of concrete according to a cracked sectional analysis $\left(d_{f c t}\right.$ in Fig. 5a) but, in all cases, the crack extends at least up to one-half of the effective depth of the member. This fact can be observed in Figs. 3 and $5 b$ where $d_{f c t}$ is calculated according to Appendix B of this paper. The angle of the primary flexural cracks $(\beta)$ is variable, becoming flatter when the acting bending moment reduces for a given level of shear force, refer to Fig. 5c. This trend shows some scatter, yet it can be reasonably approximated by the following analytical expression: 
Table 1

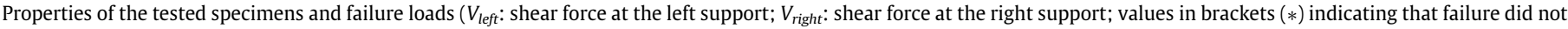
develop at that side; parameter $M /(V \cdot d)$ refers to internal forces at support; CCDT refers to the Critical Crack Development Type).

\begin{tabular}{|c|c|c|c|c|c|c|c|c|c|c|}
\hline Test & $l(\mathrm{~mm})$ & $a(\mathrm{~mm})$ & $M / V \cdot d(\mathrm{~mm})$ & $f_{c}(\mathrm{MPa})$ & $\rho(\%)$ & $q(\mathrm{kN} / \mathrm{m})$ & $V_{\text {left }}(\mathrm{kN})$ & $\mathrm{V}_{\text {right }}(\mathrm{kN})$ & Remarks & CCDT \\
\hline SC51a & 5600 & & & 33.6 & 0.886 & 60.4 & 169 & $(169)$ & 1st failure near left support & $(4)$ \\
\hline SC51b & 5600 & & & 33.6 & 0.886 & 57.8 & $(162)$ & 162 & 2nd failure near right support & (2) \\
\hline SC52 & 5600 & & 1.68 & 36.8 & 0.886 & 59.5 & $(133)$ & 200 & Diagonal cracking near right support & (1) \\
\hline SC52a & 5600 & & & 36.8 & 0.886 & 77.1 & 173 & $(259)$ & 1st failure near left support & (2) \\
\hline SC52b & 5600 & & & 36.8 & 0.886 & 85.0 & $(190)$ & 286 & 2nd failure in the central part & (4) \\
\hline SC53 & 5600 & & 2.88 & 33.2 & 0.886 & 40.2 & $(68)$ & 158 & Maximum load followed by failure & $(2)$ \\
\hline SC54 & 5600 & & 3.78 & 36.5 & 0.886 & 40.6 & $(46)$ & 182 & Maximum load followed by failure & (4) \\
\hline \multirow[t]{2}{*}{ SC55 } & 5600 & & 4.48 & 33.7 & 0.886 & 33.4 & (19) & 168 & Diagonal cracking near right support & $(3-1)$ \\
\hline & & & & & & 38.5 & $(22)$ & 194 & Failure near right support & $(2)$ \\
\hline SC56 & 5600 & & 5.04 & 35.3 & 0.886 & 28.2 & $(-)$ & 158 & Maximum load followed by failure & (3) \\
\hline SC57 & 4900 & & 4.41 & 33.2 & 0.886 & 30.0 & $(-)$ & 147 & Maximum load followed by failure & $(2)$ \\
\hline SC59 & 3500 & & 3.15 & 35.5 & 0.886 & 52.3 & $(-)$ & 183 & Maximum load followed by failure & $(2)$ \\
\hline SC62 & 2800 & & 2.52 & 35.8 & 0.886 & 62.1 & $(-)$ & 174 & Maximum load followed by failure & (4) \\
\hline SC63 & 3500 & & 3.13 & 33.6 & 0.544 & 60.8 & $(-)$ & 213 & Yielding of longitudinal reinforcement & $(-)$ \\
\hline SC61 & & 2450 & 4.41 & 35.3 & 0.886 & & $(-)$ & 103 & Maximum load followed by failure & (4) \\
\hline \multirow[t]{2}{*}{ SC64 } & & 1750 & 3.15 & 35.6 & 0.886 & & $(-)$ & 108 & Diagonal cracking (maximum load) & $(3-1)$ \\
\hline & & & & & & & $(-)$ & 105 & Failure after reloading & $(2)$ \\
\hline SC65 & & 1750 & 3.13 & 35.5 & 0.544 & & $(-)$ & 102 & Maximum load followed by failure & (3) \\
\hline
\end{tabular}

(a)

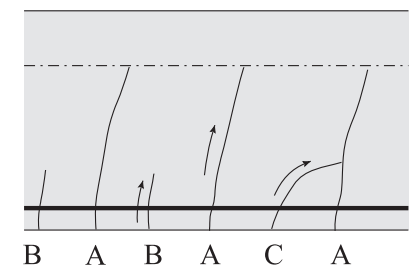

(b)

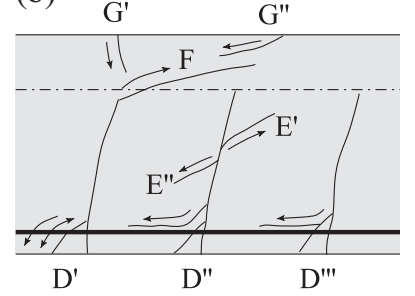

Fig. 4. Crack types: (a) primary and secondary flexural cracks; and (b) cracks originated by the shear-transfer actions.

$$
\beta=\operatorname{atan}\left(1+1.25 \frac{M(x)}{V(x) \cdot d}\right)
$$

where $\beta$ (Fig. 5a) is calculated as the angle of a line passing through point A (Fig. 5a, at the flexural reinforcement level) and the point of the actual crack at a vertical distance equal to $d / 2$ from point $A$. A comparison of this expression and the test results is shown in Fig. 5c (average of measured-to-predicted values equal to 0.99 with a Coefficient of Variation of $10 \%$ ).

Fig. $5 \mathrm{f}$ plots additionally the distribution of measured distance between flexural cracks type A. It can be observed that this distance normally varies between 0.4 and 0.8 times $d$, for all the investigated slenderness, loading types and reinforcement ratios, in accordance to previous experimental observations of [35]. The average value is $0.56 d$ with a standard deviation of $0.16 d$.

- Type B (Fig. 4a): Secondary flexural cracks. These cracks are located in between two primary flexural cracks or near the supports of the specimen. They develop for advanced loading stages and usually their height is lower than those of type A (below one-half of the effective depth of the member as assumed here). The spacing between primary and secondary flexural cracks is governed at the level of the reinforcement by bond conditions and the amount of reinforcement.

- Type C (Fig. 4a): Secondary or primary flexural cracks merging with another primary flexural crack. This case develops when a crack type A or B develops at such an angle and distance that it eventually becomes connected to another crack type A.

- Type D (Fig. 4b): Delamination (dowelling) crack developing at the level of the flexural reinforcement. Three different possibilities could be observed for this crack type (Fig. 4b):

- Type $\mathrm{D}^{\prime}$ with an inclined crack developing from the surface of the specimen to a primary flexural crack (type A). These cracks developed systematically as soon as the cracks type A started to develop in an inclined manner (after appearance of a quasi-vertical branch, refer to Fig. $4 \mathrm{~b}$, or if they were inclined from the beginning). These cracks can be originated at the level of the reinforcement (specimens SC59 and SC64, propagating both upwards and downwards) or at the specimen surface. They appear normally at low load levels, clearly below the failure load (for vertical relative displacements at the level of the reinforcement lower than $0.15 \mathrm{~mm}$ ).

- Type $\mathrm{D}^{\prime \prime}$ with the delamination crack developing above an inclined crack.

- Type $\mathrm{D}^{\prime \prime \prime}$ with the delamination crack developing from a secondary inclined crack.

Cracks type $\mathrm{D}^{\prime \prime}$ or $\mathrm{D}^{\prime \prime \prime}$ were usually observed to develop (according to photogrammetric measurements) after the maximum load was reached, but not at maximum load or before it.

- Type E (Fig. 4b): Aggregate-interlock induced cracks. These cracks can develop at both sides of an existing crack (refer to types $E^{\prime}$ and $E^{\prime \prime}$ ) and usually originate from a primary or secondary flexural cracks transferring shear by aggregate interlock. The development and origin of such cracks has been recently traced by Jacobsen et al. [36]. According to refined photogrammetric measurements on notched specimens (refer to Fig. 6, adapted from [36]), when an existing pure tension crack (mode I) is subsequently subjected to shear displacements (mixed mode I and II), inclined cracks develop due to the local aggregate interlock forces. These inclined interlock cracks develop according to the geometry of the original tension crack and potentially at both sides of the crack (Fig. 6e). Similar crack developments and shape have been observed in the beams presented in this paper.

According to the literature, the capacity of cracked concrete to transfer shear and normal forces through aggregate interlocking is strongly influenced by the opening and roughness of the crack. Fig. 7 presents for instance the calculated interface stresses according to the approaches of various authors [14,22,23]. That will be used later in this paper. In spite of some differences, all models yield a similar trend, with decreasing interlock stresses for increasing crack opening and/or decreasing sliding.

- Type F (Fig. 4b): Propagation of a primary flexural crack within the compression chord. This usually happens with a rather flat crack originating from a primary flexural crack. The length of 
(a)

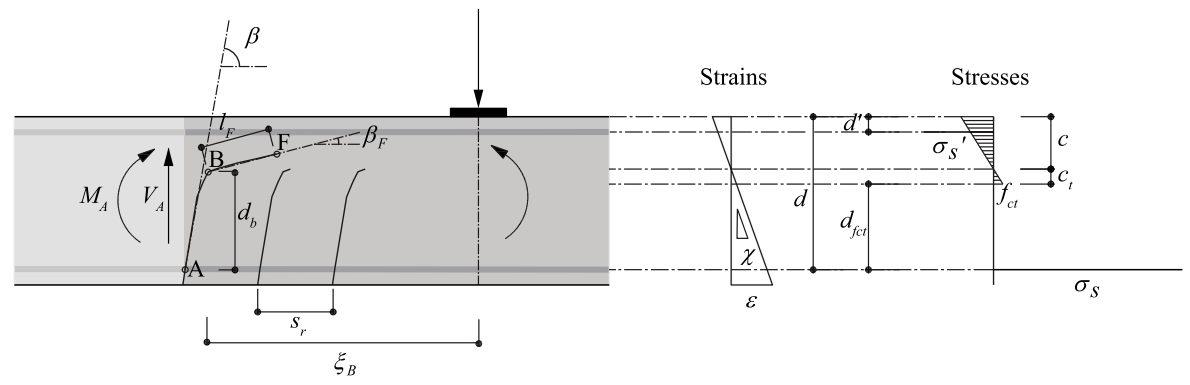

(b)

$\frac{d_{b}}{d_{f c t}}[-]$

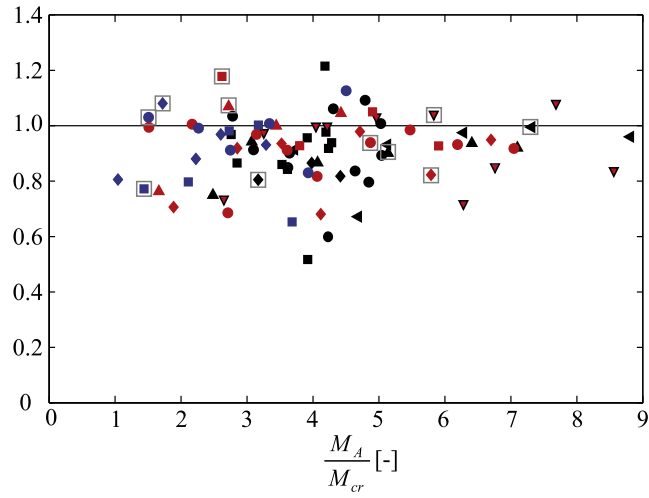

(d)

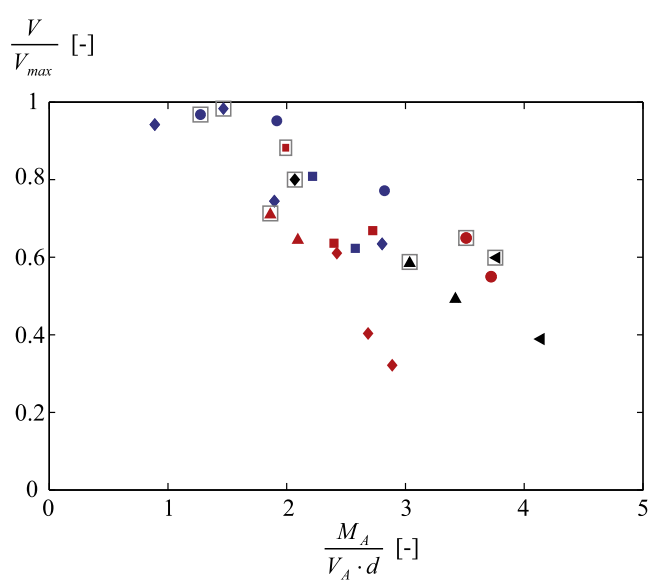

(c)

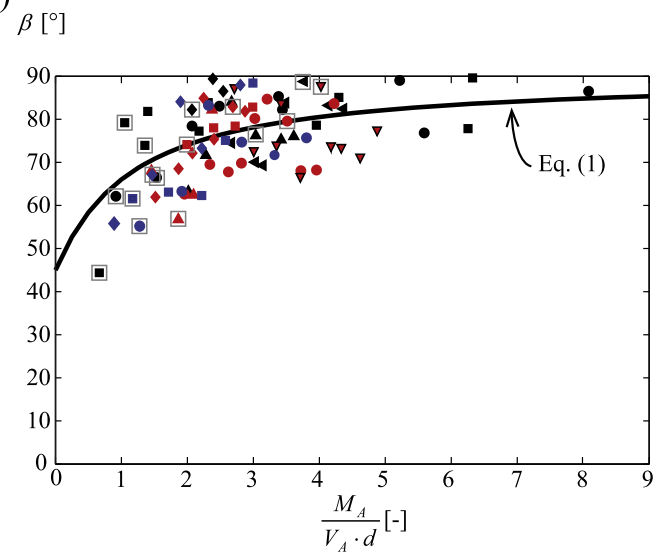

(e)

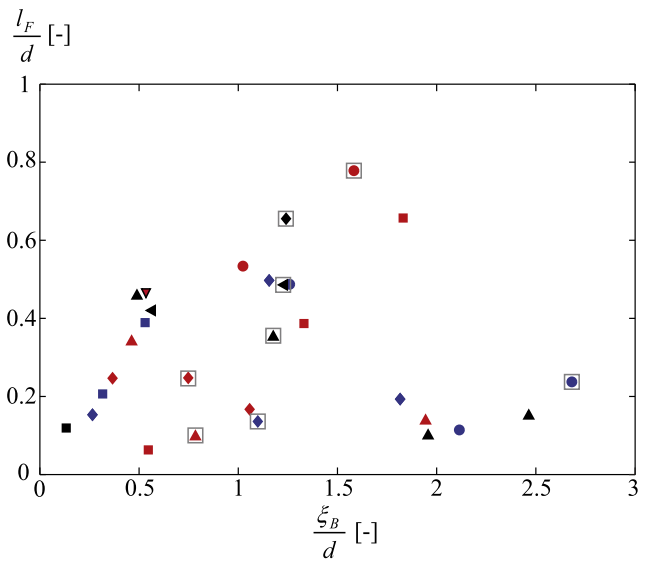

(f)
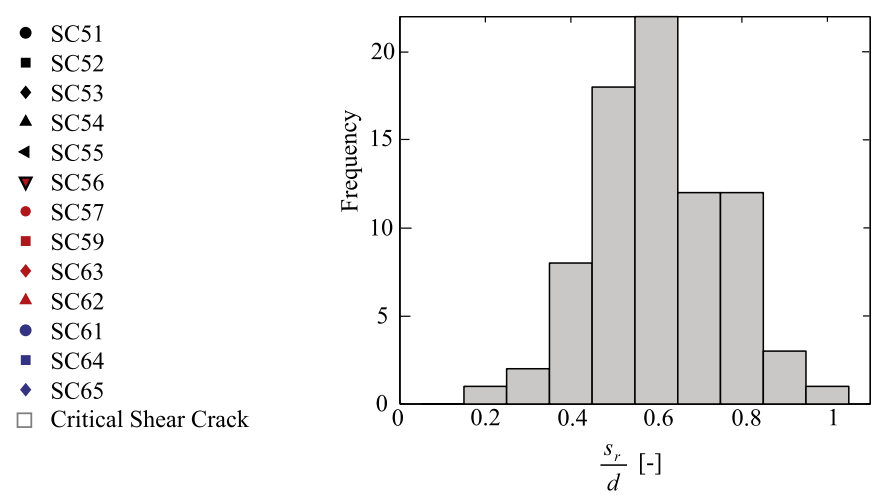

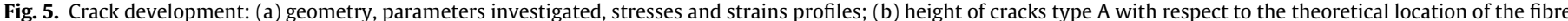

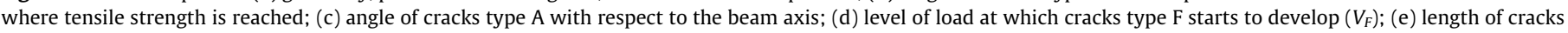

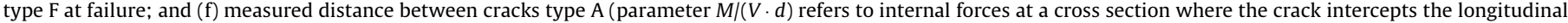
reinforcement). 
(a)

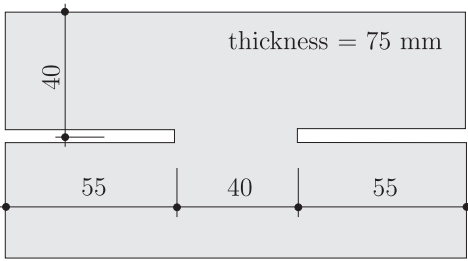

(c)

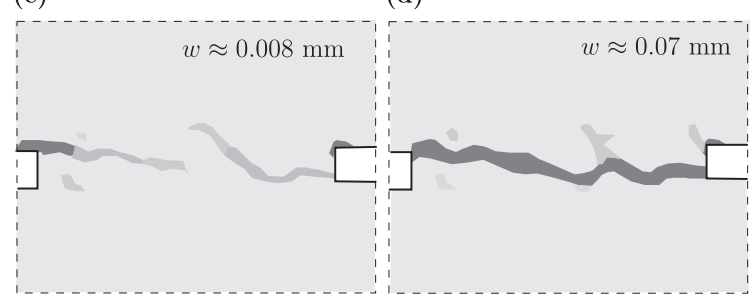

(b)

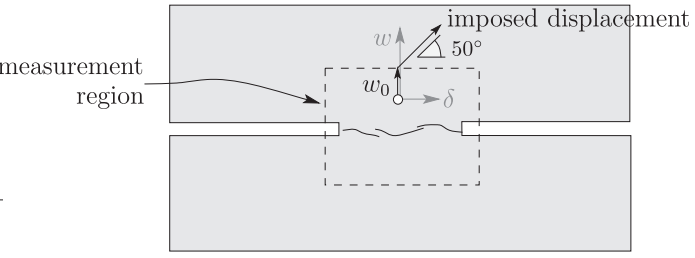

(e)

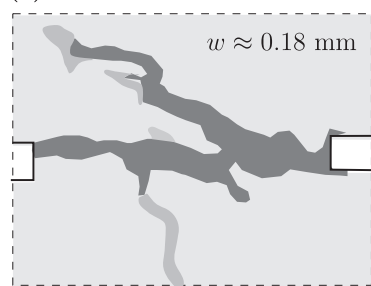

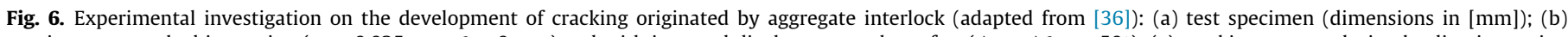

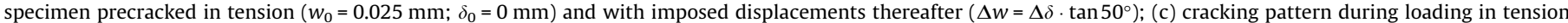

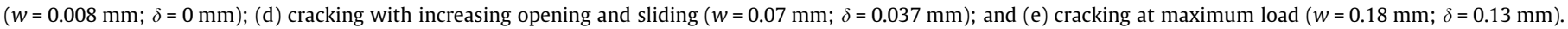

cracks type $\mathrm{F}$ at maximum load was relatively variable (generally varying between $0.05 d$ and $0.8 d$, refer to Fig. 5e) as well as its angle with respect to the axis of the member (generally varying between $5^{\circ}$ and $50^{\circ}$, and in between $5^{\circ}$ and $30^{\circ}$ in cases when crack types $\mathrm{F}$ became critical). Despite the scatter, some trends can however be observed. For instance, as Fig. 5e shows, when the cracks are close to the load introduction region $\left(\xi_{B}<0.5 d\right.$ in Fig. 5e), the length of the crack type $\mathrm{F}$ is limited by its distance to the load ( $\xi_{B} \approx \ell_{F}$ in Fig. 5e). When the cracks are located at larger distances $\left(0.5 d<\xi_{B}<2 d\right.$ in Fig. 5e), there exists a correlation between the length of the crack $F$ and its distance to the load (with increasing length of the crack for larger distances, refer to Fig. 5e). Finally, for relatively large distances of the crack to the load $\left(\xi_{B}>2 d\right.$ in Fig. 5e) the length of the crack type F drastically reduces to values around 0.2 times $d$ (Fig. 5e).
The level of load at which propagation of a crack type F started was dependent on the acting moment-to-shear ratio. This is shown in Fig. 5d, where the ratio amongst the load for beginning of this crack with respect to the failure load is plotted against the acting moment-to-shear ratio at the section where crack A crosses the reinforcement. It can be observed that cracks type $\mathrm{F}$ propagated at load levels close to failure for low values of the acting moments (crack near support or point of moment inflection) whereas it developed already for relatively low levels of load when the acting bending moment was significant. More details on this topic will be provided in next section.

- Type G (Fig. 4b): Development of a crack within the compression chord but not originating from a primary flexural crack. These cracks usually develop perpendicular to the edge of the slab $\left(G^{\prime}\right.$, due to local bending of the compression chord as (b)

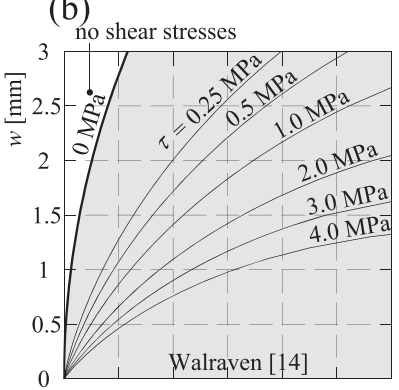

(c)

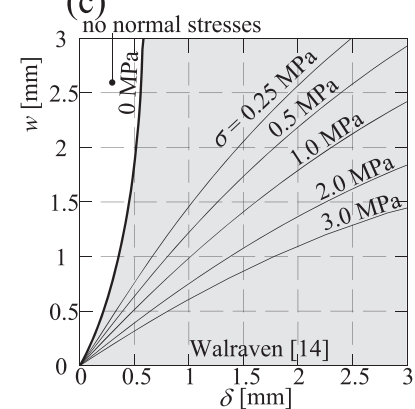

(d)

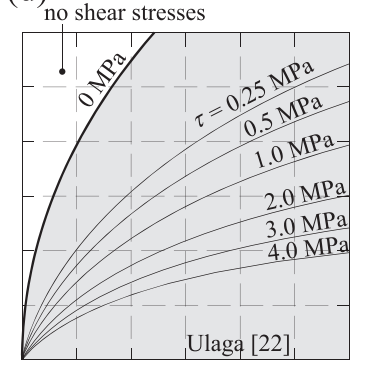

(e)

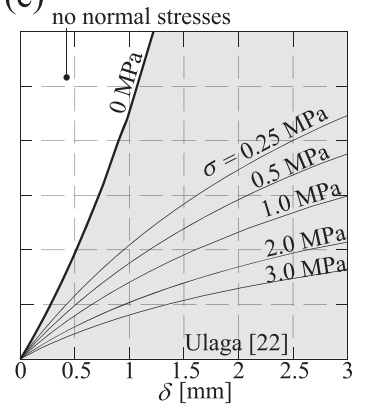

(f)

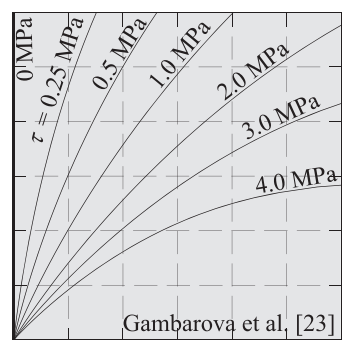

(g)

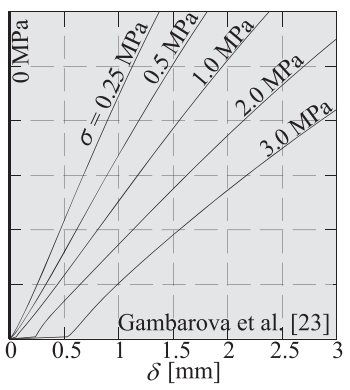

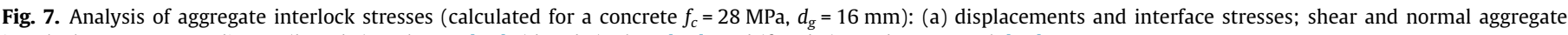
interlock stresses according to (b and c) Walraven [14]; ( $\mathrm{d}$ and e) Ulaga [22]; and (f and g) Gambarova et al. [23]. 
explained in [32]) or at flat angles near the load introduction region $\left(G^{\prime \prime}\right.$, due to the large shear forces in the compression chord and/or crushing of the compression chord).

\section{Measured crack development and kinematics at failure}

By means of the photogrammetry measurements, the development of cracks could be accurately tracked before failure and, particularly, in the seconds before and after reaching the maximum load. Several evolutions of the cracking patterns have been observed. These patterns are not consistent amongst them and even present large differences. It was observed in all cases the development of a critical shear crack progressing to failure, yet in different manners. The critical shear crack refers to an existing crack (usually type A-E or A-F) whose opening leads eventually to the failure of the specimen. It can be noted that the final failure surface is not always identical to the critical shear crack (as it can be intercepted or merged to other cracks during the process of failure), but it is at least partly coincident with it. This failure surface will be referred as the failure crack in order to distinguish it from the critical shear crack.

\subsection{Potential critical shear crack allowing direct strut action to develop (Critical Crack Development Type (1))}

Whenever a direct strut action (Fig. 1b) can develop without being disturbed by the presence of a shear crack, the plastic solution to shear strength [21] can develop [32]. This case was for instance observed in specimen SC52 near the right support, Fig. 8. The beam developed a diagonal crack $\left(A_{1}\right.$ in Fig. 8$)$ at the positive bending moment region for a load $q=59.5 \mathrm{kN} / \mathrm{m}$, leading to a small drop in the applied load (about 4\%). This crack however did not become critical, as the specimen could be reloaded and failure cracks developed at other places for higher levels of load ( $q=77.1 \mathrm{kN} / \mathrm{m}$ and $q=85 \mathrm{kN} / \mathrm{m}$, refer to Table 1 and Fig. 3). The reason for the shear crack not to become critical can be found in the possibility of developing a direct strut action in the uncracked region above the crack (the point of contraflexure of bending moments was located at approximately $2 d$ from the edge of the intermediate support). It is interesting to note from the crack relative displacements that hardly any aggregate interlock stresses developed in this crack as there was almost no crack sliding (refer to Fig. 7).

A similar case occurred also for specimen SC64 and SC55. After a first failure triggered by the propagation of an aggregate interlockoriginated crack, the specimens could be reloaded up to $97 \%$ of the failure load for specimen SC64 and up to 115\% for specimen SC55.

Similar cases have been reported elsewhere [32], for beams with cracks developing at locations such that the inclined struts of the arching action can develop undisturbed. This behaviour clearly shows the significant dependence of the shear strength on the crack location and shape.

\subsection{Failures following a stable propagation of a critical shear crack (Critical Crack Development Type (2))}

Specimen SC59, Fig. 9, failed in shear after a crack type F propagated in a stable manner from the critical shear crack. This crack originated from a primary flexural crack (crack $A_{1}$ in Fig. 9) who merged a crack type $C$ at approximately $82 \%$ of the failure load (refer to crack $C_{1}$ in Fig. 9). Then, the primary flexural crack develop at a flatter angle as a crack type $F\left(F_{1}\right.$ in Fig. 9) until failure. At that moment, also a delamination crack appeared (crack $D_{1}{ }^{\prime \prime \prime}$ in Fig. 9). Measurements on the crack relative displacements indicate that aggregate interlock stresses were potentially developing along the steeper part of the crack $A_{1}$ since large crack sliding occurred (Fig. 7). It is also interesting to note that the critical shear crack eventually reached the location of the compression reinforcement, and it could potentially also develop some dowelling action of the top reinforcement prior to failure (refer to the delamination cracks in the top part of Fig. 9).

Other specimens exhibiting the stable propagation of the critical shear crack were tests SC51b and SC52a. In addition, such stable crack propagation was also observed for specimens SC53 (Fig. 10) and SC57 (Fig. 11). Particularly for specimen SC53, aggregate interlock stresses could be mobilized at the critical shear crack

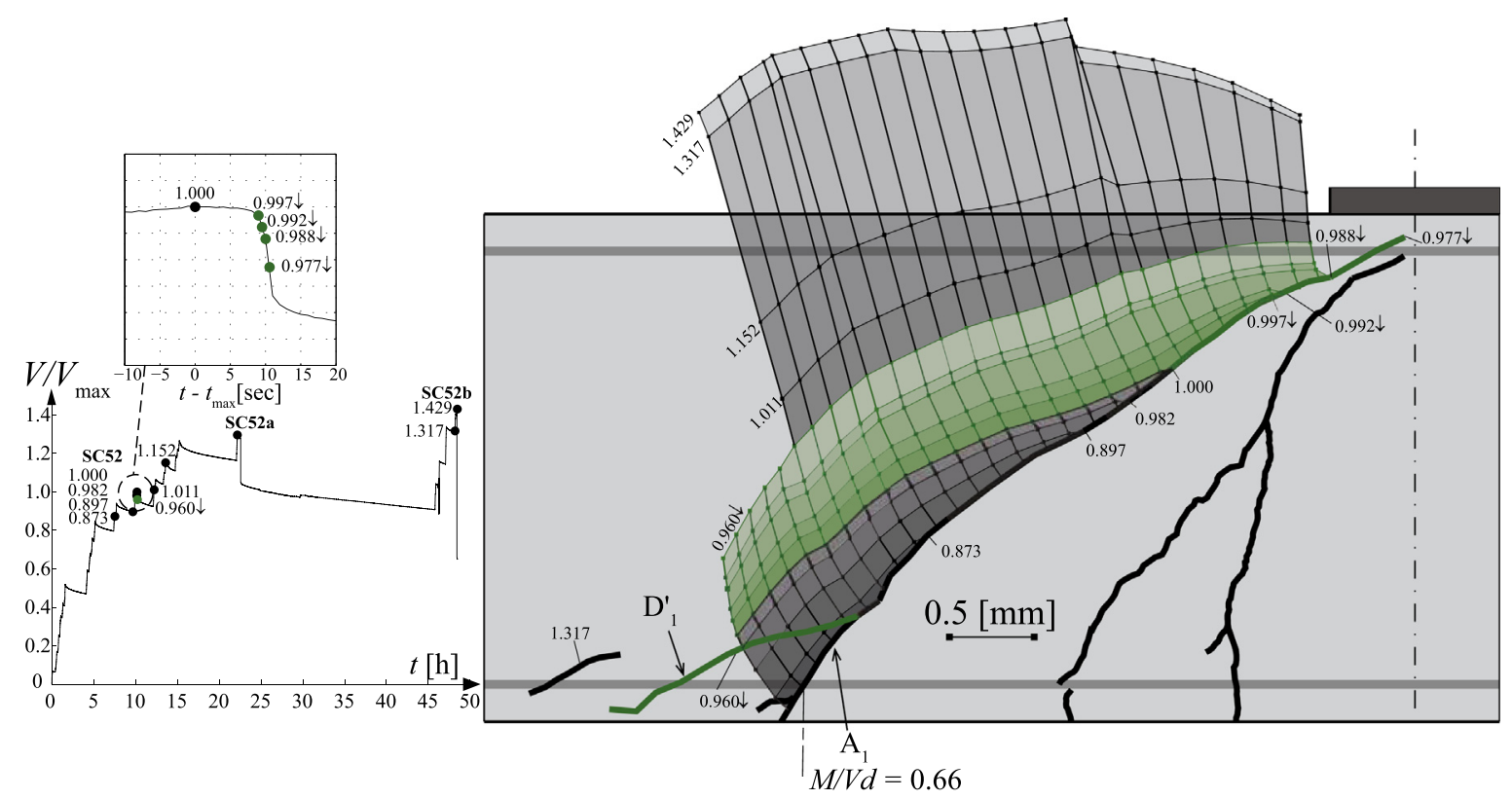

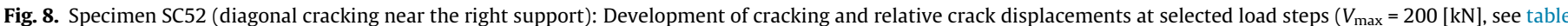

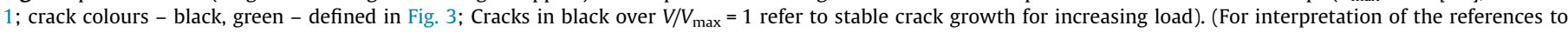
colour in this figure legend, the reader is referred to the web version of this article.) 


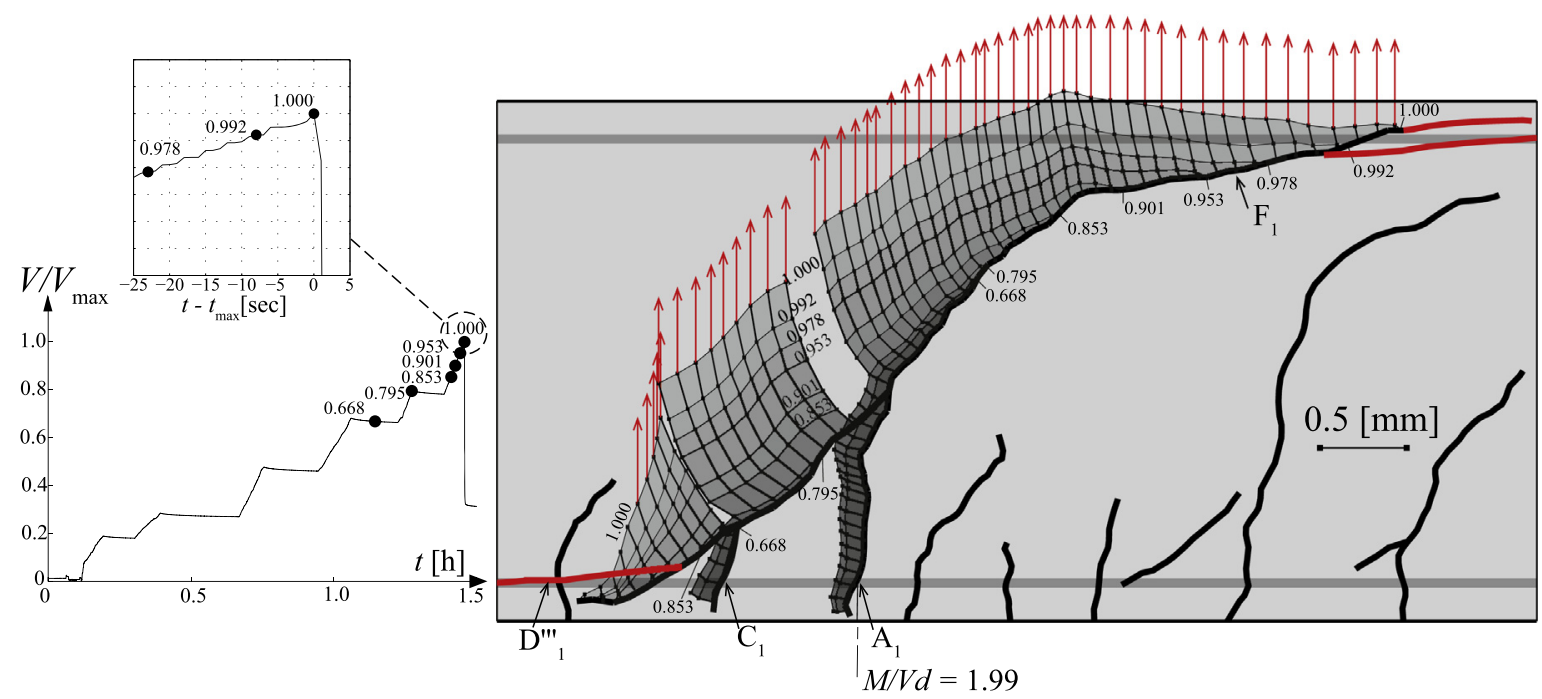

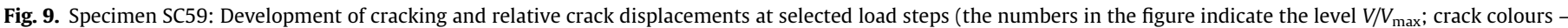

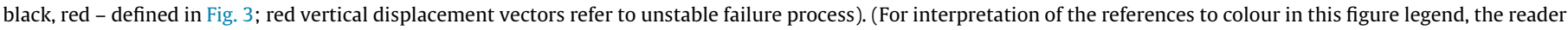
is referred to the web version of this article.)

accounting for its relative displacements. Failure was for this specimen followed by the development of a delamination crack $\mathrm{D}_{1}{ }^{\prime \prime \prime}$ along the top reinforcement (Fig. 10).

\subsection{Failures driven by loss of aggregate interlock capacity due to} development of an interlock crack (Critical Crack Development Type (3))

In some regions of the critical shear cracks, large interlock stresses could be mobilized. For some specimens, the concentrations of aggregate-interlock stresses led to the propagation of a new crack, eventually leading to the failure of the specimens. These cracks (inclined cracks developing from a crack originated in bending) are in fact in agreement to the inclined cracks observed to develop from the first (tension-induced) crack as shown in Fig. 6e by Jacobsen et al. [36].
This can for instance be observed in specimen SC65. As Fig. 12 shows, a well-defined critical shear crack was already formed and stable (crack $A_{2}$ with a small delamination crack type $\mathrm{D}_{2}^{\prime}$ ). The measurement of relative displacements of the crack faces of the critical shear crack indicated also large potential aggregate interlock stresses being activated (crack sliding under low crack openings in Fig. 7). As a result, a new crack developed suddenly in this region ( $E_{2}^{\prime \prime}$, drawn in blue in Fig. 12) at approximately $99 \%$ of the failure load. This can be clearly observed in the detailed photogrammetric measurements of Fig. 13. As a consequence, the interlock stresses dropped and failure was triggered by a progression of the critical shear crack into the compression chord (crack $F_{2}$ in Fig. 12). At that moment (after maximum load), a new delamination crack (type $\mathrm{D}_{2}^{\prime \prime \prime}$ ) also formed on the bottom reinforcement (above $\mathrm{D}_{2}^{\prime}$ ), as well as on the top reinforcement.

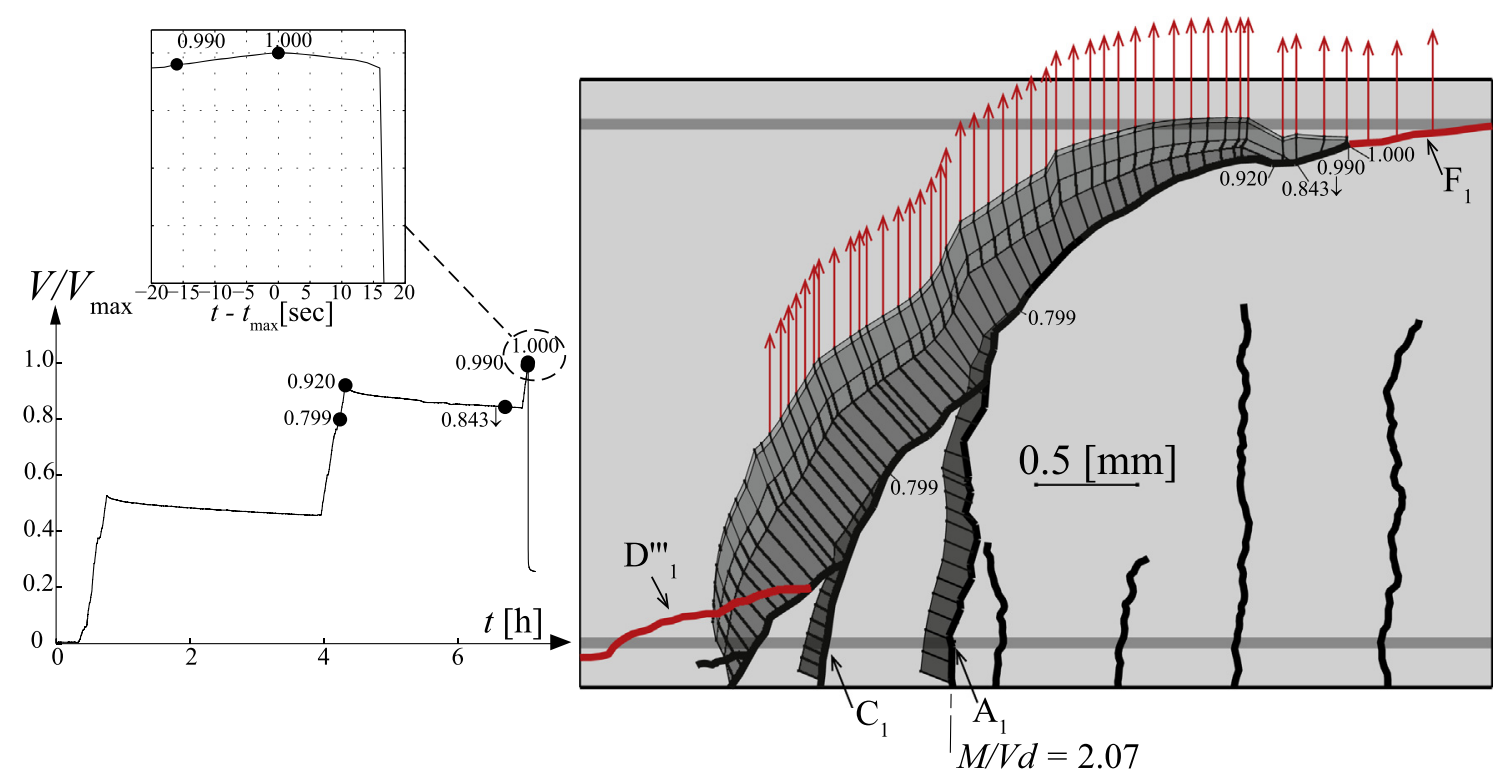

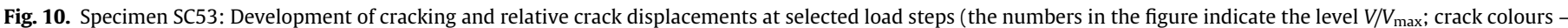

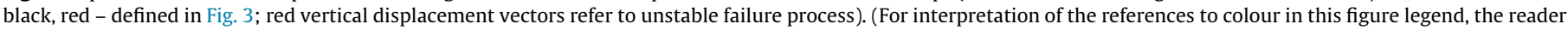
is referred to the web version of this article.) 


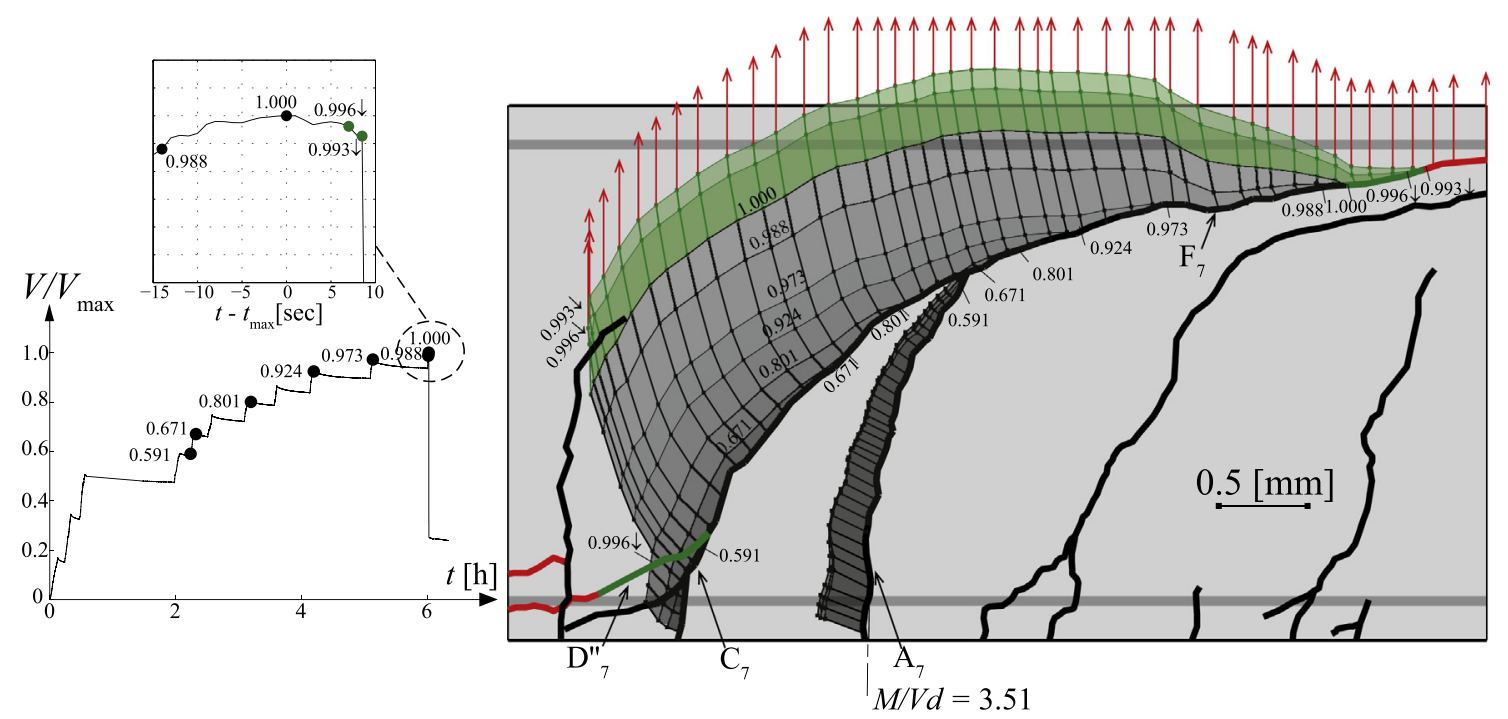

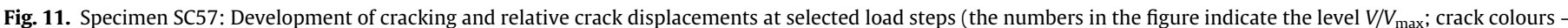

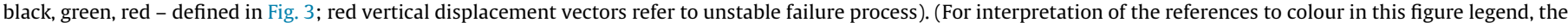
reader is referred to the web version of this article.)

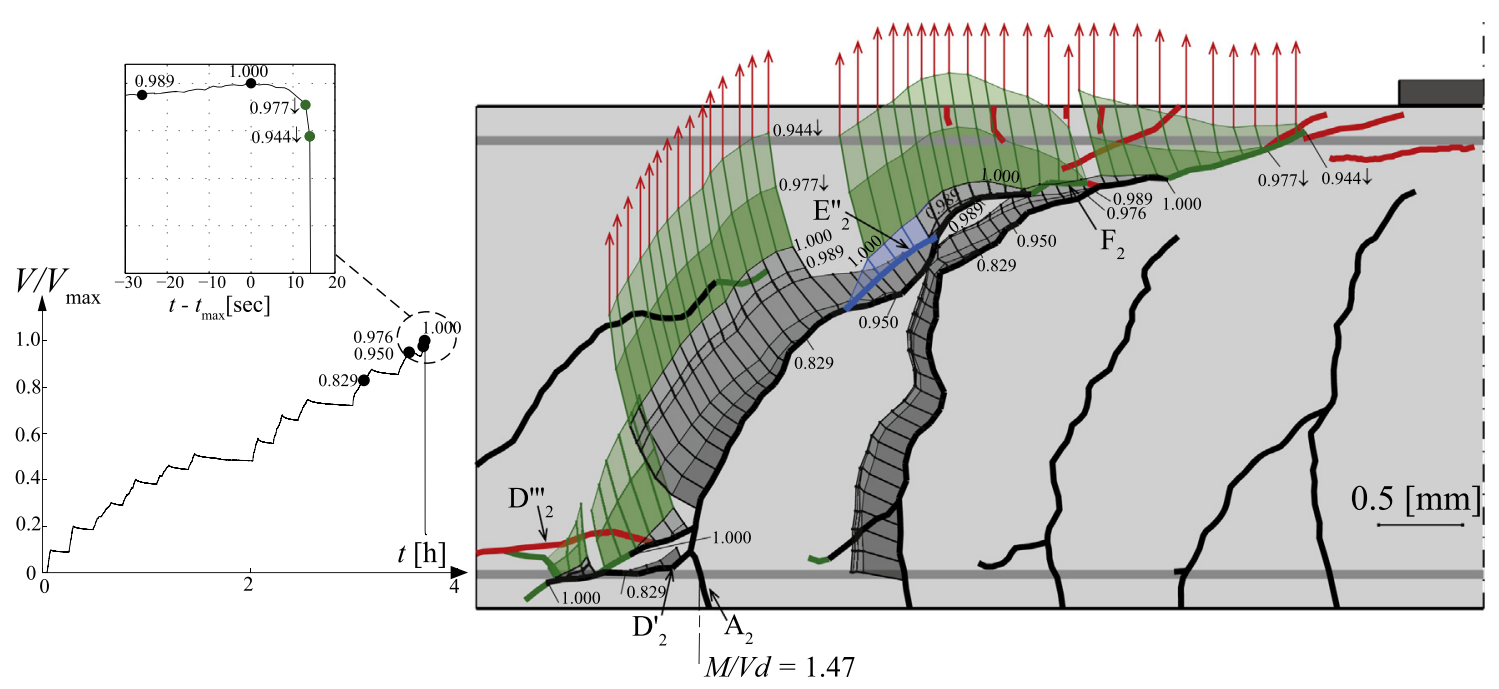

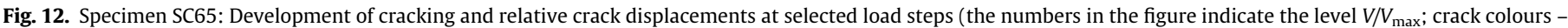

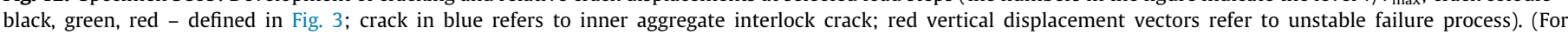
interpretation of the references to colour in this figure legend, the reader is referred to the web version of this article.)

The same development of cracking due to loss of aggregate interlock was also observed for specimens SC56 and SC63 (yielding of the longitudinal reinforcement was however governing for the strength of the latter). Specimen SC64 also presented a similar failure mode (Fig. 15). Yet, in this case, the diagonal crack type $\mathrm{E}$ (crack $E_{1}^{\prime}$ in Fig. 15) was originated from a flexural crack $\left(A_{1}\right)$ which was less developed (as the acting bending moment was lower at the location of that crack). After the diagonal crack $\mathrm{E}_{1}^{\prime}$ developed and a drop of the load occurred, the specimen could be reloaded (Fig. 15) but the load could not be increased above the previous one.

It can be noted that also the diagonal crack (first failure) of specimens SC55 (crack $E_{5}^{\prime}$ Fig. 14) was also due to the development of an aggregate-interlock crack. This specimen could however be reloaded to a higher level due to the critical shear crack shape (refer to Critical Crack Development Type (1)).

\subsection{Failures driven by merging of flexural cracks type A and C (Critical} Crack Development Type (4))

This failure type has been observed for specimens SC61, SC62, SC51a, SC52b and SC54. A representative case is that of specimen SC62 shown in Fig. 16. In this specimen, a primary flexural crack (crack $\mathrm{A}_{2}$, Fig. 16) was clearly developed at already $80 \%$ of the failure load. Aggregate-interlock stresses could be activated (sliding of the crack lips) but only in the vertical parts of the crack due to its kinematics (corresponding to a location of the instantaneous centre of rotations at the tip of the crack). At this load level, a secondary flexural crack started to progress in an inclined manner. Eventually, this crack merged the primary flexural crack becoming thus a crack type $C$ (crack $C_{2}$ in Fig. 16). When both cracks merged, a significant portion of crack $A_{2}$, whose geometry and kinematics allowed to carry shear forces by aggregate interlock 

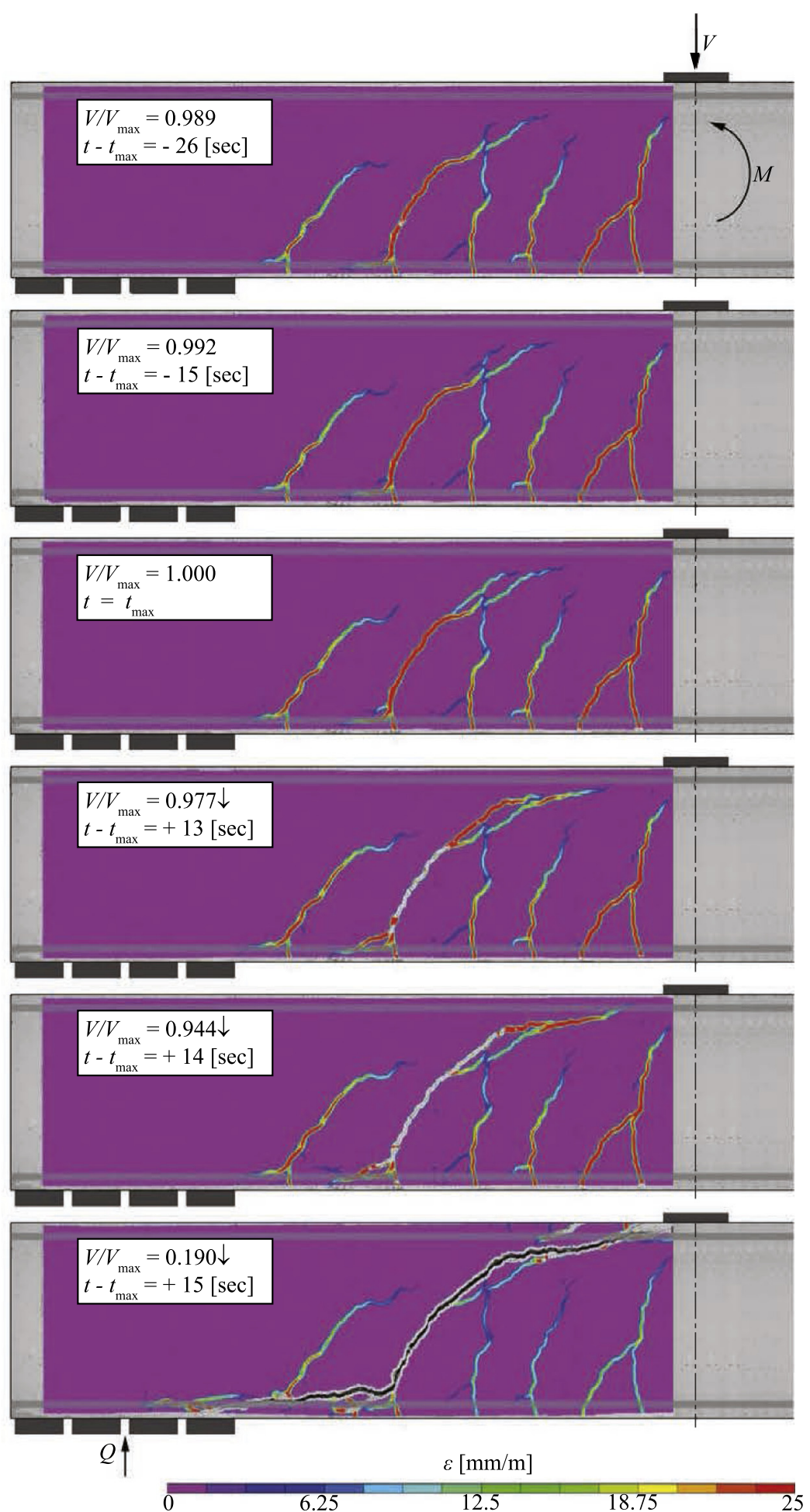

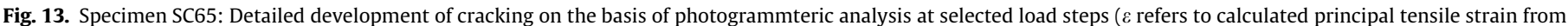
photogrammetric measurements).

(quasi-vertical part below the merging point), was deactivated. Merging of both cracks occurred at maximum load. At that moment, the opening of crack $A_{2}$ increased abruptly, and even a new interlock-type crack $\left(\mathrm{E}_{2}^{\prime}\right)$ developed aligned with the crack $\mathrm{C}_{2}$ deactivating another vertical portion of crack $A_{2}$ where shear forces were carried. Both phenomena (increase of crack opening and new crack development) led to a loss of the aggregate interlock capacity. In addition, a delamination crack (type $\mathrm{D}_{2}^{\prime \prime}$ ) originated and progressed after maximum load was reached. During failure, a number of cracks type $\mathrm{G}^{\prime \prime}$ (Fig. 16) also developed in the compression zone. The process of failure, with merging of the cracks $C_{2}$ and $A_{2}$, as well as the development of crack $E_{2}^{\prime}$, can clearly be appreciated on the sequence of pictures shown in Fig. 17 on the basis of the photogrammetric measurements.

For specimen SC54 (Fig. 18) failure occurred also when the crack type $\mathrm{C}$ merged with the crack type A. This increased the 


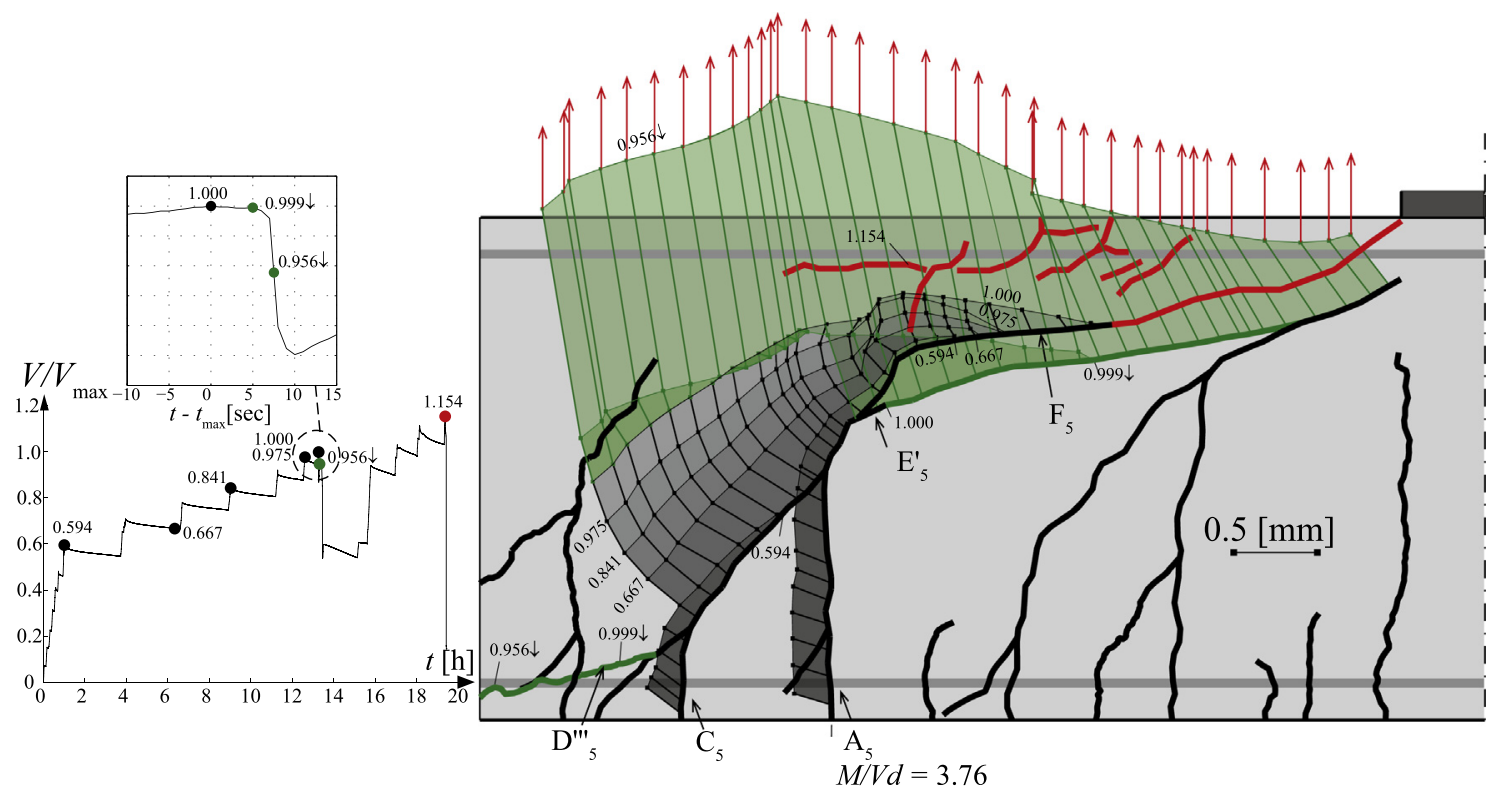

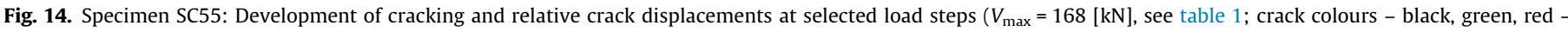

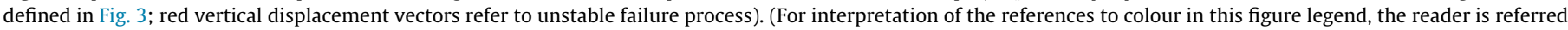
to the web version of this article.)

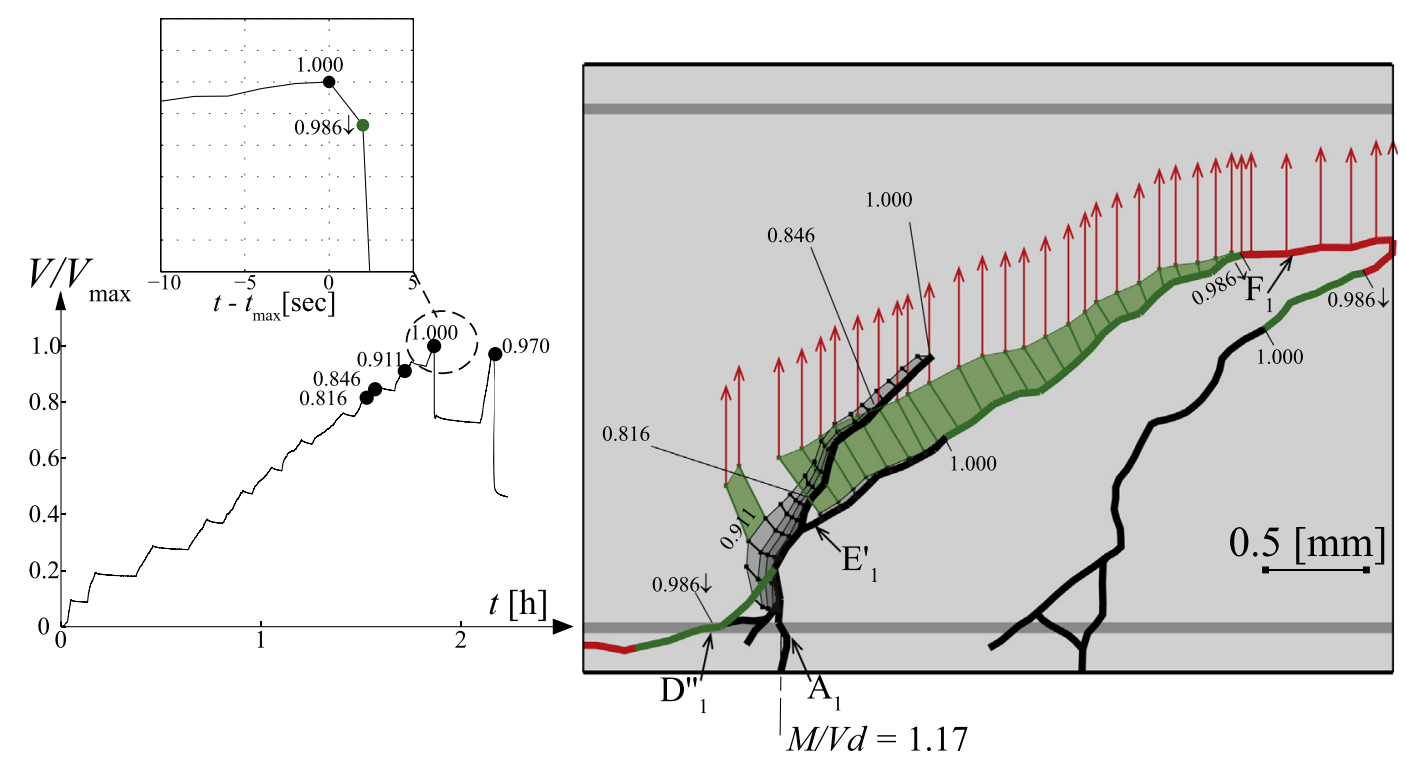

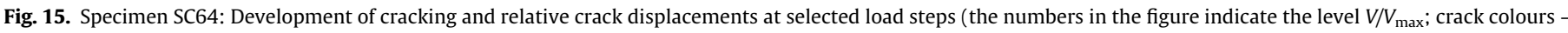

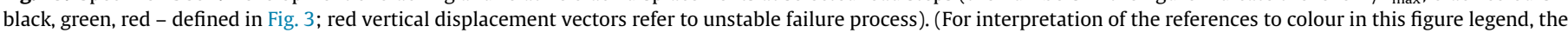
reader is referred to the web version of this article.)

opening of the critical shear crack and led to failure (yet no aggregate-interlock crack (type E) developed).

A similar case was also found for specimen SC61, refer to Fig. 19. In that specimen, a primary flexural crack $\mathrm{A}_{1}$ developed and progressed in a stable manner as a crack type $F\left(F_{1}\right.$ in Fig. 19). Aggregate interlock stresses could be mobilized according to the crack kinematics at the steeper branch, where significant sliding with low crack openings occurred (particularly near the inflexion point) (refer to Fig. 7). Also, residual tensile stresses of concrete were potentially possible between the tip of the crack and the inflexion point accounting for such low crack openings (stresses in pure tension, mode I). However, at a certain moment, a new crack (crack $C_{1}$ in Fig. 19) appeared and progressed in an inclined manner. The origin of this crack could be possibly a combination of bending and dowelling forces. It progressed rapidly and eventually merged the primary flexural crack (becoming thus a crack type C) leading to failure with a sudden increase of the opening of the critical shear crack (and thus a total loss of aggregate-interlock capacity).

\section{Critical analysis on the role of shear-transfer actions and mechanical modelling based on test observations}

On the basis of the previous observations, it can be stated that different kinematics may govern at failure. In addition, it cannot be excluded that cracking patterns and kinematics at failure differ- 


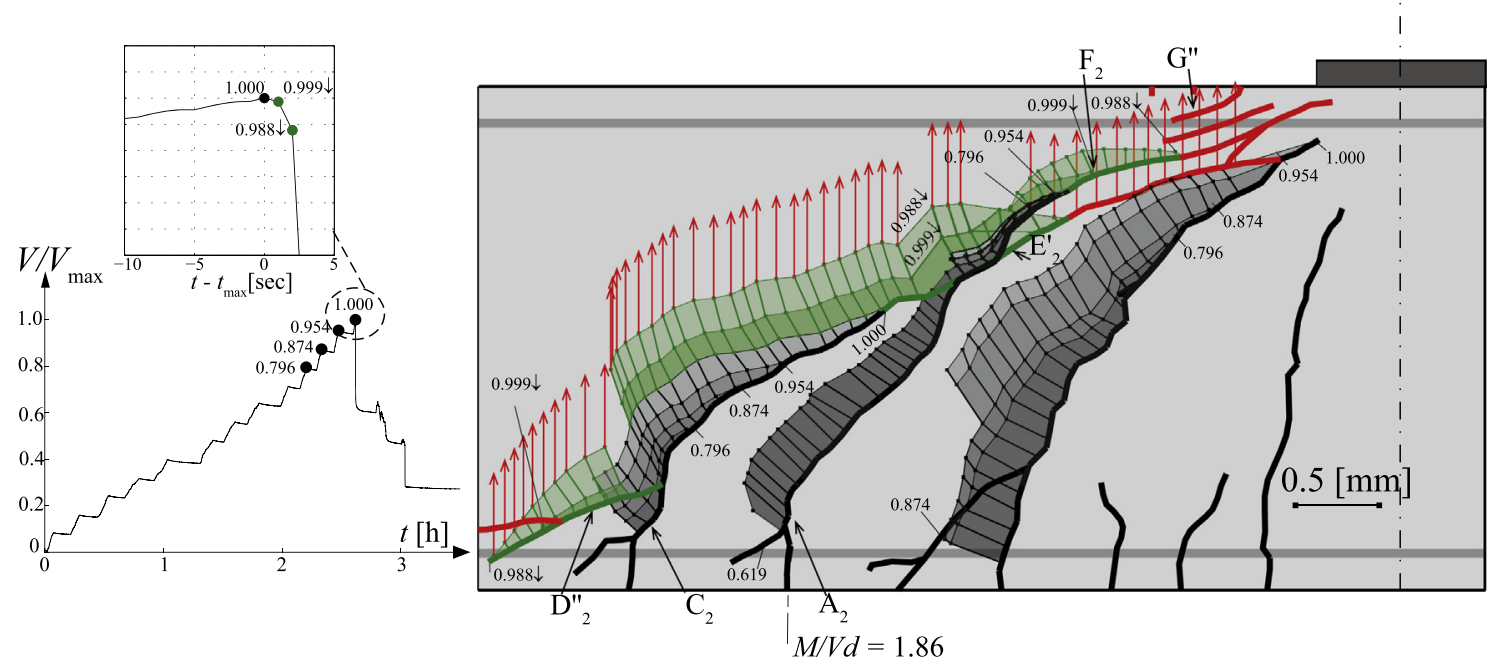

Fig. 16. Specimen SC62: Development of cracking and relative crack displacements at selected load steps (the numbers in the figure indicate the level $V / V_{\text {max }}$; crack colours black, green, red - defined in Fig. 3; red vertical displacement vectors refer to unstable failure process). (For interpretation of the references to colour in this figure legend, the reader is referred to the web version of this article.)
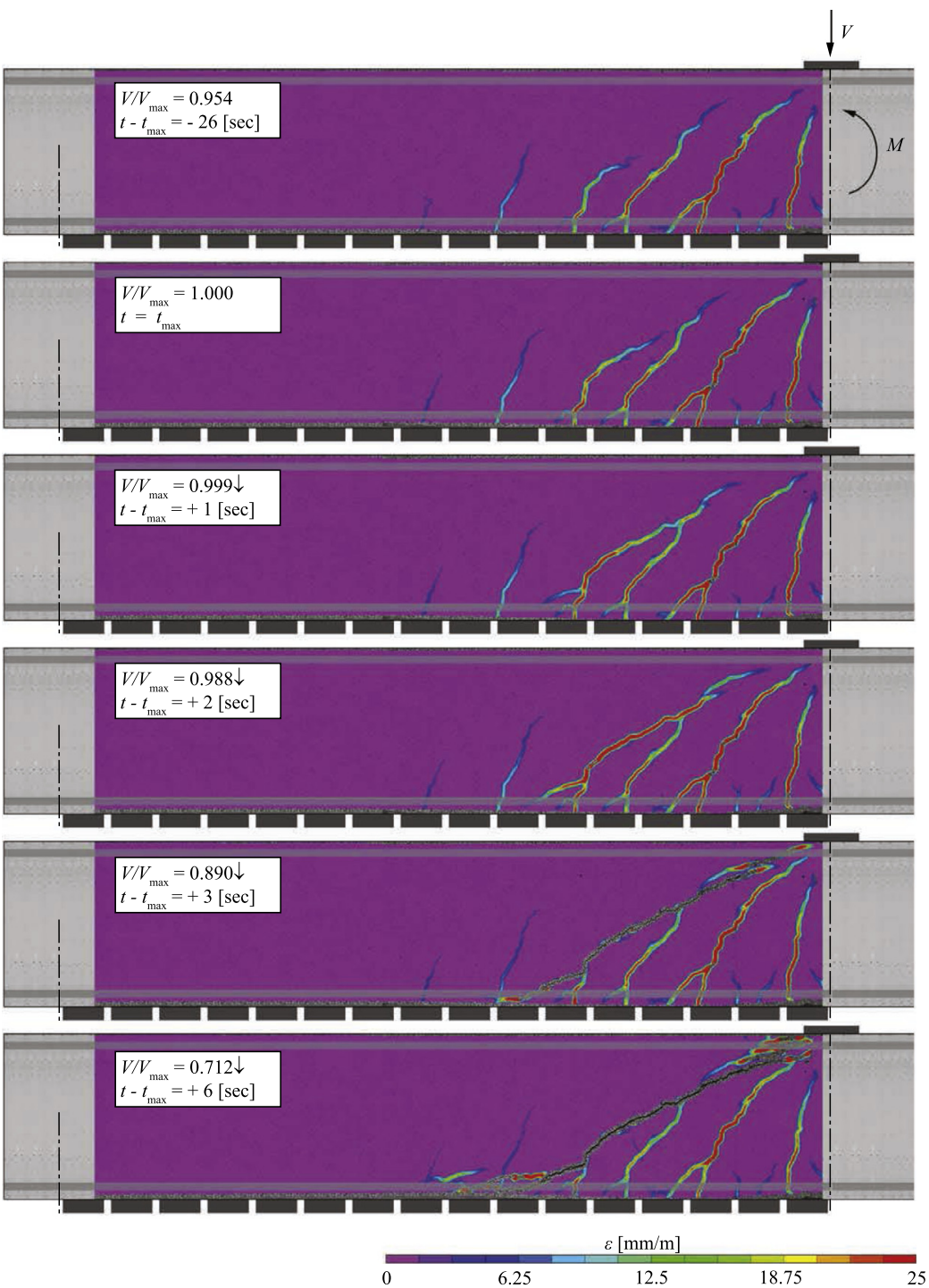

Fig. 17. Specimen SC62: Detailed development of cracking on the basis of photogrammteric analysis at selected load steps ( $\varepsilon$ refers to calculated principal tensile strain from photogrammetric measurements). 


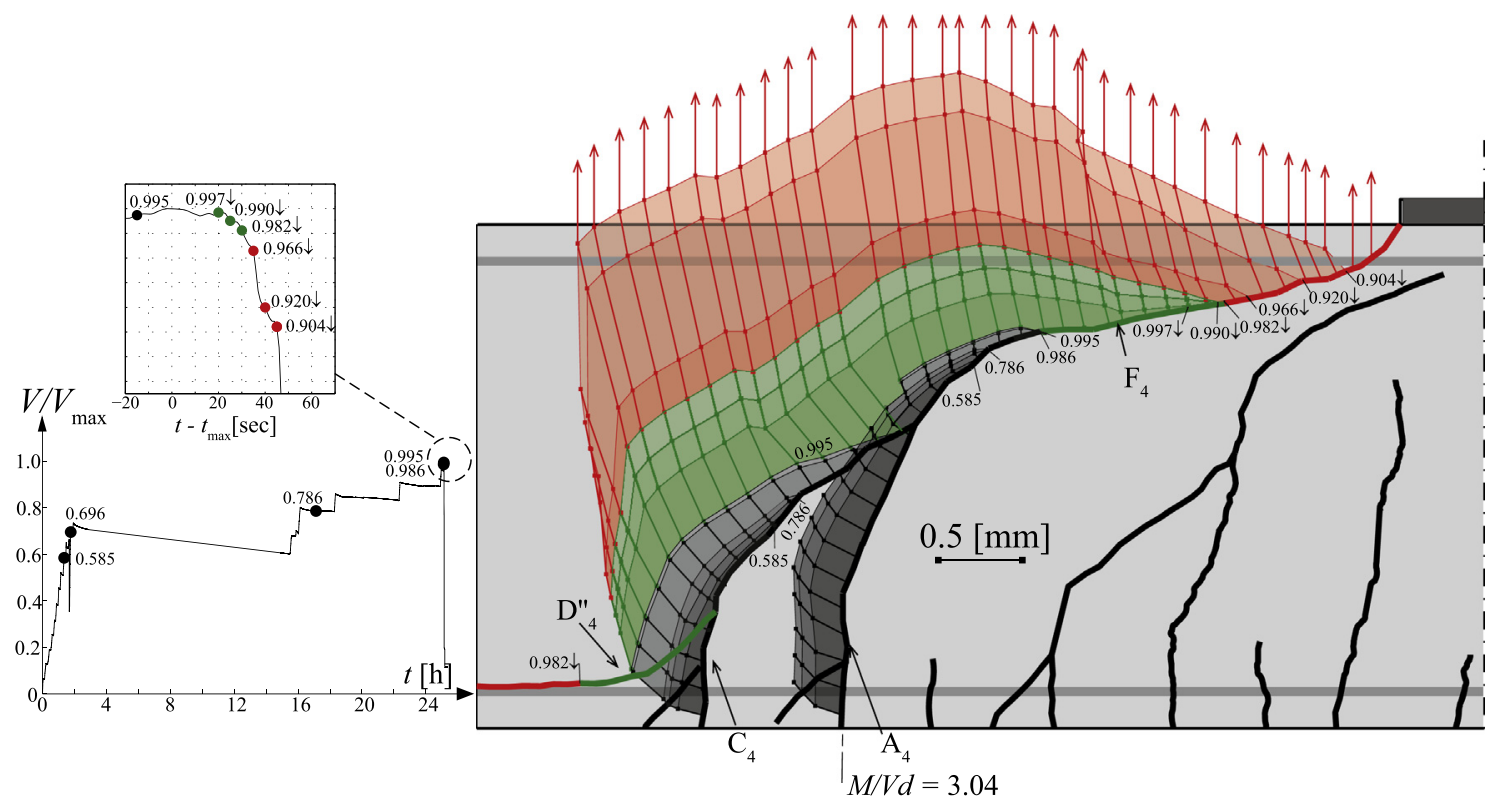

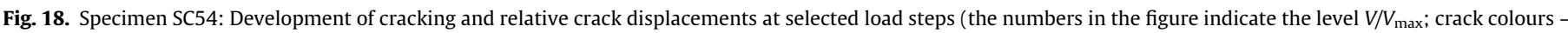

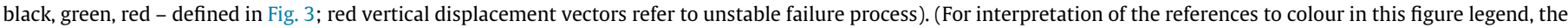
reader is referred to the web version of this article.)

ent to those previously described could have potentially been observed for beams tested with other parameters (size, slenderness, tensile and compression reinforcement ratio, aggregate size, cross section, bond behaviour between rebars and concrete...). This implies that different potential shear-transfer actions may be more or less active on the shear strength of a member depending on the actual cracking pattern and its associated kinematics.

It is also noticeable that the strength provided by different failure modes and even different shear-transfer actions may lead to similar strengths. That was for instance observed for specimen SC64, where first failure (propagation of an aggregate interlock crack) and reloading, with a completely different crack geometry and kinematics, provided a similar strength, with only $3 \%$ difference. Yet, the load configuration and support conditions significantly influence the level of shear at which failure occurs for the same cross-section and flexural reinforcement (Table 1), contrary to many code formulas for shear design $[5,6]$.
With respect to the suitability of the shear-transfer actions (and the associated modelling approaches), a critical comparison shows that they account reasonably for some cases yet they fail in explaining others:

- Aggregate interlock seems very reasonable to explain sheartransfer for Critical Crack Development Types (2) and (3) as well as some cases of Type (4). This fact is supported by the observed crack pattern and kinematics. Also, Fig. 20 compares the calculated contribution of aggregate interlock to the total measured shear resistance for some selected specimens. The analyses are performed following the methodology presented in Campana et al. [37] and for different aggregate-interlock models [14,22,23] (refer to Fig. 7). As Fig. 20 shows, the contribution of aggregate interlock is variable, more significant for some specimens than for others. In some cases, almost all shear force could be explained by this shear-carrying action, although

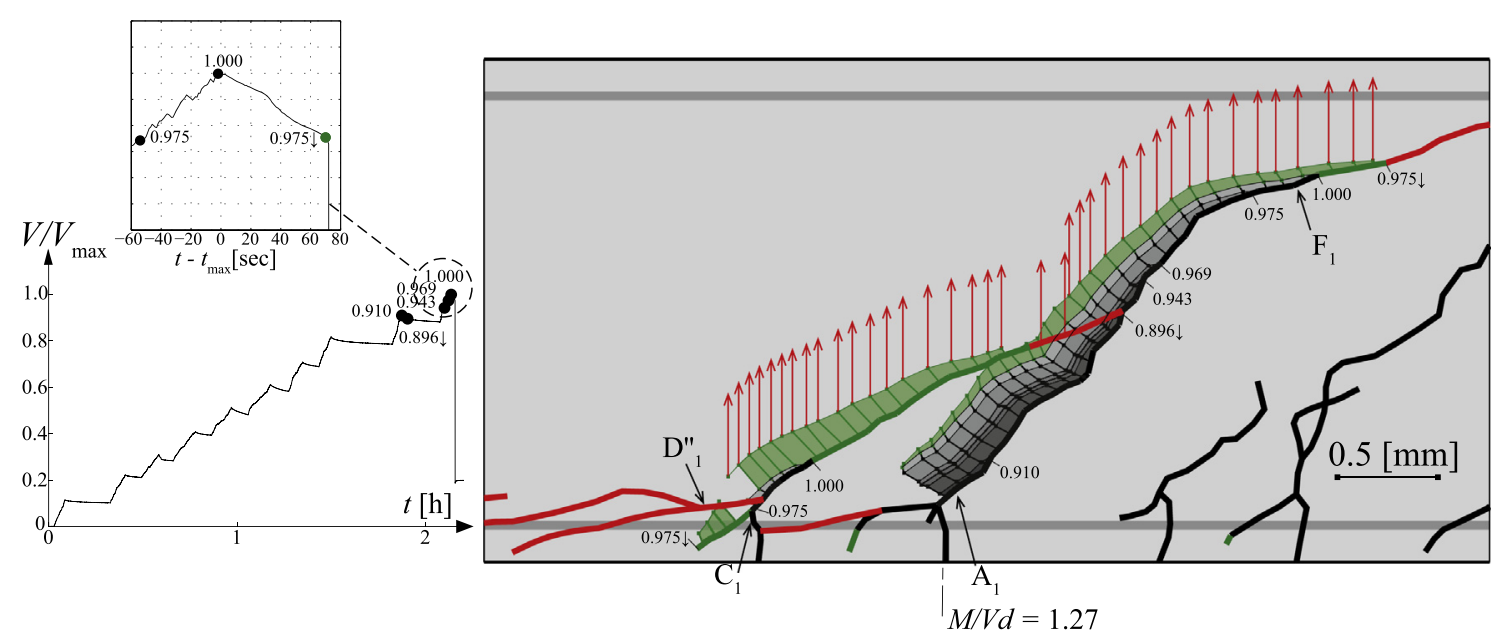

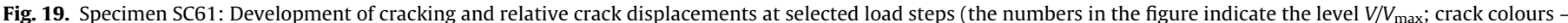

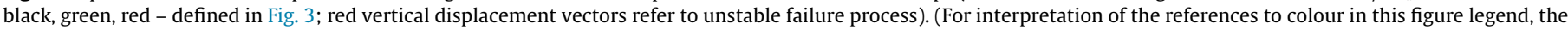
reader is referred to the web version of this article.) 


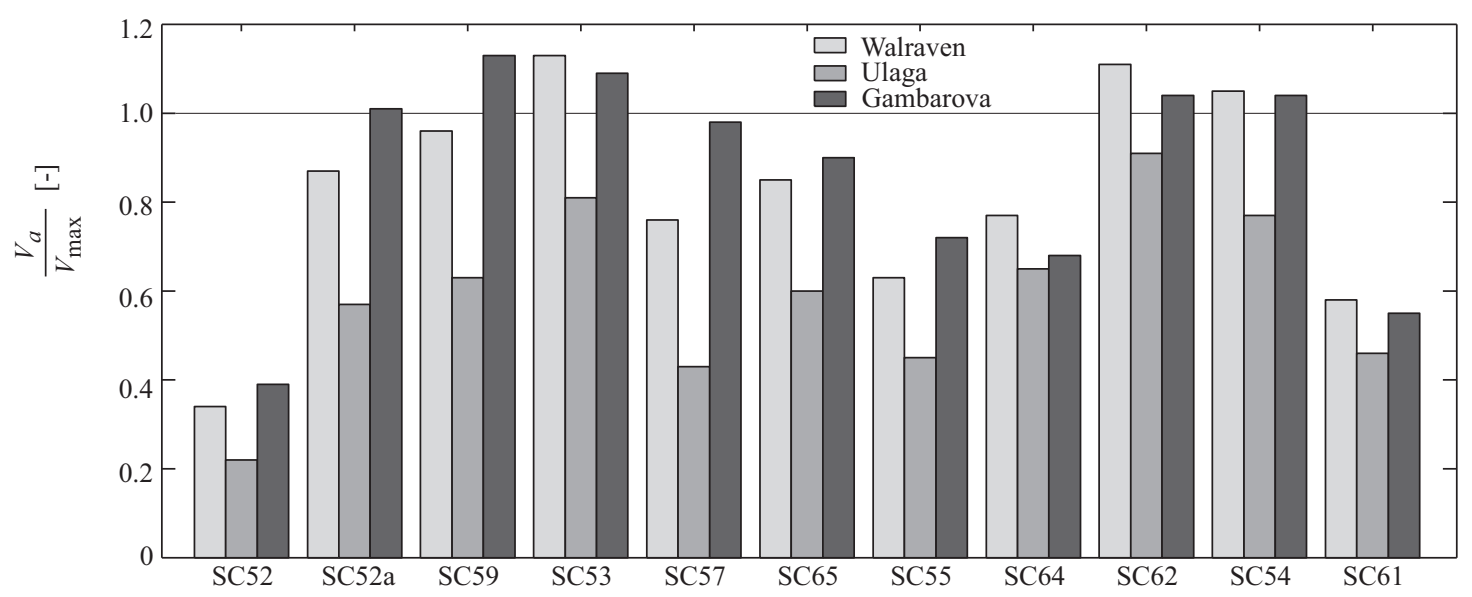

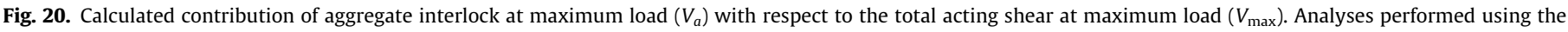

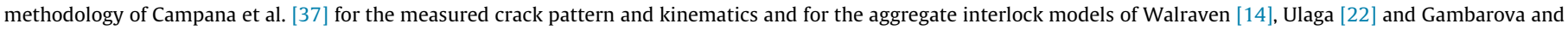
Karakoç [23] (refer to Fig. 7).

for others this contribution was relatively moderate. These results are in agreement to those presented in [37], although it can be noted that the models overestimate the contribution of aggregate interlock (in some specimens, according to Walraven's and Gambarova's models, the calculated contribution is larger than the acting shear force).

- When a secondary flexural crack merges with a primary one (Critical Crack Development Type (4)), the additional opening of the critical shear crack as well as its change of shape (to a more straight one) limit the possibility of developing the aggregate-interlock stresses, deactivating portions of crack type A where significant shear forces could be carried, and potentially triggers failure (in agreement to [27]).

- The contribution of the compression chord can be observed as very active particularly when the critical shear crack develops such that a direct strut action is possible. This refers to Critical Crack Development Type (1).

- The role of dowelling action of the tensile reinforcement seems potentially notable for short-span beams when the failure crack is close to the supported area (refer for instance to specimens SC65, SC64 and SC63). A significant influence of cracks related to dowelling action (type D) seems in fact that it increases the opening of the critical shear crack (due to the unbonded length over the delaminated zone), weakening other shear-transfer actions as aggregate interlock. Cracks type $\mathrm{D}^{\prime \prime}$ or $\mathrm{D}^{\prime \prime \prime}$ however have been observed in most tests to develop after reaching of the maximum load. Also, some contribution can be expected for dowelling of the compression reinforcement when the failure crack reaches its level.

These findings from the present experimental programme explain why different mechanical approaches might lead to similar results in terms of strength. This is consistent with the analyses performed by Campana et al. [37] which showed that the governing shear-transfer actions may be rather different even for identical specimens depending on the cracking pattern and associated kinematics.

\section{Conclusions}

This paper presents detailed measurements on the crack development and kinematics of beams during the process of failure. The measurements allow identifying different governing failure modes and their potentially governing shear-transfer actions. The main conclusions of this investigation are listed below:

1. Detailed investigation on the role of the shear-transfer actions and the suitability of mechanical models should be based not only on the cracking pattern after failure, but should account for the development of cracking (geometry and kinematics) right before and during the process of failure.

2. Photogrammetry is a very suitable tool for that purpose, allowing detailed tracking of cracks and analysis of the crack kinematics.

3. The experimental measurements show that failure may occur in different manners. Even, some specimens reloaded after a first failure are capable of developing alternative shear-transfer actions with a strength comparable in some cases to the one leading to first failure. This is particularly significant with respect to the capacity of the compression and tension chords (combined arching and dowelling actions).

4. Cracking due to bending (location, inclination and crack opening) plays a major role on the shear strength. The angle of the bending cracks is influenced by the level of shear forces.

5. Aggregate interlock depends mainly on the crack geometry and its kinematics (with the vertical upper parts of the crack carrying more shear forces). This shear transfer action can be limited by development of new cracks starting from an existing one.

6. It cannot be identified a unique shear-transfer action governing shear strength based on the performed tests. This makes in fact all actions to influence the failure strength and mode. Nevertheless, an analysis based on existing aggregate-interlock models and accounting for the actual cracking pattern and kinematics at failure shows that aggregate interlock may play a significant role in many of the investigated specimens.

7. On the basis of the test results, consistent modelling of shear strength should in principle account for all potential sheartransfer actions as well as for their dependence on the cracking state, pattern and development.

\section{Acknowledgement}

The authors would like to gratefully acknowledge the support and funding of the Swiss Federal Road Authority, through the project AGB-2011-015. 


\section{Appendix A. Notation}

a shear span (defined for specimens subjected to concentrated loads as the distance between the centre of the load and the centre of the support)

b beam width

c depth of compression zone

$c_{t} \quad$ depth of tension zone

$d \quad$ effective flexural depth

$d_{f c t} \quad$ location of fibre where tensile strength of concrete is attained (measured from the tension side)

$d_{g} \quad$ maximum aggregate size

$d^{\prime} \quad$ distance from the compression reinforcement to the concrete surface

$f_{c} \quad$ concrete compressive strength measured in cylinder

$f_{c t} \quad$ concrete tensile strength

$h$ beam height

$q \quad$ distributed load

$l$ span length

$t$ time of test

$t_{\max }$ time at which maximum load is attained

$w \quad$ crack width

$E_{c} \quad$ modulus of elasticity of concrete

$E_{S} \quad$ modulus of elasticity of steel

$M$ bending moment

$N$ normal force

Q concentrated load

$V \quad$ acting shear force

$V_{\text {left }} \quad$ shear force at the left support

$V_{\max }$ shear force at failure (maximum value)

$V_{\text {right }}$ shear force at the right support

$V_{a} \quad$ contribution of aggregate-interlock stresses to shear resistance

$V_{c} \quad$ contribution of inclined compression chord to shear resistance

$V_{d} \quad$ contribution of dowelling action to shear resistance

$V_{F} \quad$ level of shear at which crack type F develops

$V_{t} \quad$ contribution of residual tensile stresses to shear resistance

$\beta \quad$ angle of flexural cracks with respect to the beam axis

$\chi \quad$ curvature

$\delta \quad$ Relative crack sliding

$\rho$ reinforcement ratio of tension reinforcement

$\rho^{\prime} \quad$ reinforcement ratio of compression reinforcement

$\sigma \quad$ normal component of aggregate-interlock stresses

$\sigma_{s} \quad$ stress in the tension reinforcement

$\sigma_{s}{ }^{\prime} \quad$ stress in the compression reinforcement

$\tau \quad$ shear component of aggregate-interlock stresses

$\xi_{B} \quad$ location (distance) of point B

\section{Appendix B. Location of the fibre where the tensile strength of concrete is reached in bending}

In this Appendix, the theoretical location of the fibre where concrete reaches its tensile strength following a pure bending analysis is presented. The following hypothesis are accepted (Fig. 5a):

- Concrete has a linear-elastic behaviour in compression (characterized by its modulus of elasticity $E_{c}$ ). In tension, the behaviour of concrete is linear until the tensile strength $\left(f_{c t}\right)$ is reached. Thereafter, the concrete exhibits no residual tensile strength. - Plane sections before cracking remain plane after cracking.

\section{- Tension-stiffening effects are neglected.}

According to compatibility conditions, plane sections remain plane, the following condition can be established:

$f_{c t}=\chi \cdot c_{t} \cdot E_{c}$

The equilibrium of moments and normal forces yield additionally:

$N=0=-\frac{c^{2}}{2} b \cdot \chi \cdot E_{c}+\frac{f_{c t}^{2} \cdot b}{2 \chi \cdot E_{c}}+\chi \cdot b \cdot d \cdot E_{s}\left(\rho \cdot(d-c)+\rho^{\prime} \cdot\left(d^{\prime}-c\right)\right)$

$M=\frac{c^{3}}{3} b \cdot \chi \cdot E_{c}+\frac{f_{c t}^{3} \cdot b}{3 \chi^{2} \cdot E_{c}^{2}}+\chi \cdot b \cdot d \cdot E_{s}\left(\rho \cdot(d-c)^{2}+\rho^{\prime} \cdot\left(d^{\prime}-c\right)^{2}\right)$

where $c$ and $c_{t}$ can be calculated by solving numerically the Eqs. (3) and (4) for a given acting moment $M$. From those values the location of $d_{f c t}$ (location of fibre where $f_{c t}$ is attained) results: $d_{f c t}=d-c-c_{t}$. If $f_{c t}$ is neglected $\left(c_{t}=0\right)$, a closed-form solution exists for $c$ :

$c=d \cdot\left(\rho+\rho^{\prime}\right) \frac{E_{s}}{E_{c}}\left(\sqrt{1+2 \frac{\rho+\rho^{\prime} \cdot d^{\prime} / d}{E_{s} / E_{c}\left(\rho+\rho^{\prime}\right)^{2}}}-1\right)$

leading to $d_{f c t}=d-c$.

\section{References}

[1] Ritter W. The Hennebique construction method. Schweizerische Bauzeitung, XXXIII, $N^{\circ}$ 7; 1899. p. 41-61 [in German, "Die Bauweise Hennebique"].

[2] Mörsch E. Reinforced concrete construction, theory and application. 3rd ed. Verlag von Konrad Wittwer; 1908. 376 p [in German, “Der Eisenbetonbau, seine Theorie und Anwendung"].

[3] Nielsen MP, Braestrup MW, Bach F. Rational analysis of shear in reinforced concrete beams. In: IABSE colloquium proceedings P-15, vol. 2, Bergamo, Italy; 1978. $16 \mathrm{p}$.

[4] Thürlimann B. Plastic analysis of reinforced concrete beams. In: IABSE colloquium - plasticity in reinforced concrete, reports of the working commissions, vol. 28, Copenhagen, Denmark; 1979. p. 71-90.

[5] Eurocode 2. Design of concrete structures - general rules and rules for buildings. EN 1992-1-1. Brussels (Belgium): CEN European Committee for Standardization; 2004. 225p.

[6] ACI 318. Building code requirements for structural concrete and commentary. Farmington Hills (USA): American Concrete Institute; 2011. 503 p.

[7] Chana PS. Investigation of the mechanism of shear failure of reinforced concrete beams. Mag Concr Res 1987;39(141):196-204 [London, UK, December].

[8] Fenwick RC, Paulay T. Mechanisms of shear resistance of concrete beams. J Struct Div Proc ASCE 1968;94(ST10):2325-50 [Reston, USA, October].

[9] Paulay T, Loeber PJ. Shear transfer by aggregate interlock. In: Shear in reinforced concrete, vol. 1. Detroit (USA): ACI Special Publication SP-42; 1974. p. $1-16$.

[10] Kani GNJ. The riddle of shear failure and its solution. ACI J Proc 1964;61 (4):441-68.

[11] Taylor HPJ. Investigation of the dowel shear forces carried by the tensile steel in reinforced concrete beams. Cement and Concrete Association Report No. TRA 431, London, UK; 1969. 24 p.

[12] Vecchio FJ, Collins MP. The modified compression field theory for reinforced concrete elements subjected to shear. ACI J 1986;83(March-April):219-31.

[13] Taylor HPJ. Investigation of the forces carried across cracks in reinforced concrete beams in shear by interlock of aggregate. Cement and Concrete Association, Technical Report No. 42.77, London, UK; 1970. 22 p.

[14] Walraven JC. Aggregate interlock: a theoretical and experimental investigation. PhD thesis. Delft (Netherlands): Delft University of Technology; 1980. 197 p.

[15] Bažant ZP, Kim J-K. Size effect in shear failure of longitudinally reinforced beams. ACI J 1984;81(6):456-68.

[16] Fédération Internationale du Béton (fib). Model code 2010 - final draft, vols. 1 and 2. Fédération Internationale du Béton, Bulletins 65, 66, Lausanne, Switzerland; 2012.350 p. and 370 p.

[17] SIA. Code 262 for concrete structures. Zürich: Swiss Society of Engineers and Architects; 2013. $102 \mathrm{p}$

[18] CSA Committee A23.3. Design of concrete structures (CSA A23.3-04) Mississauga: Canadian Standards Association; 2004. 214 p.

[19] Benning W, Lange J, Schwermann R, Effkemann C, Görtz S. Monitoring crack origin and evolution at concrete elements using photogrammetry. In: Proceedings of the ISPRS conference 2004, international society for photogrammetry and remote sensing, vol. B, Istanbul, Turkey; 2004. p. 678-83. 
[20] Muttoni A, Fernández Ruiz M, Niketić F. Design versus assessment of concrete structures using stress fields and strut-and-tie models. ACI Struct J 2015;112 (5):605-15.

[21] Drucker DC. On structural concrete and the theorems of limit analysis, vol. 21. Zürich: Publications, International Association for Bridge and Structural Engineering; 1961. p. 49-59.

[22] Ulaga T. Reinforced concrete elements with reinforcement composed of bars and strips: bond and tension modelling. PhD thesis. Thesis no. 15062. Zurich (Switzerland): ETHZ; 2003. 160 p [in German: Betonbauteile mit Stab- und Lamellenbewehrung: Verbund- und Zuggliedmodellierung].

[23] Gambarova PG, Karakoç C. A new approach to the analysis of the confinement role in regularly cracking concrete elements. In: Trans 7th struct mech in reactor tech, vol. H; 1983. p. 251-61.

[24] Fernández Ruiz M, Mirzaei Y, Muttoni A. Post-punching behavior of flat slabs. ACI Struct J 2013;110(5):801-12.

[25] Zararis PD. Shear strength and minimum shear reinforcement of reinforced concrete slender beams. ACI Struct J 2003;100(2) [Farmington Hills, USA, March-April].

[26] Tureyen AK, Frosch RJ. Concrete shear strength: another perspective. AC Struct J 2003;100(5):609-15 [Farmington Hills, USA, September-October].

[27] Yang Y. Shear behaviour of reinforced concrete members without shear reinforcement, a new look at an old problem. PhD thesis. Delft (Netherlands): Delft University of Technology; 2014. 344 p.

[28] Nielsen MP, Hoang LC. Limit analysis and concrete plasticity. 3rd ed. CRC Press; 2011. 796 p.
[29] Fisker J. Shear capacity of reinforced concrete beams without shear reinforcement. PhD thesis. Aarhus (Denmark): Aarhus University; 2014. 155 p.

[30] Marí A, Bairán J, Cladera A, Oller E, Ribas C. Shear-flexural strength mechanical model for the design and assessment of reinforced concrete beams. In: Structure and infrastructure engineering: maintenance, management, lifecycle design and performance. Taylor \& Francis Online; 2014. 21 p.

[31] Tue NV, Theiler W, Tung ND. Shear behaviour of bended members without transverse reinforcement. Beton- und Stahlbetonbau 2014;109(10):666-77 [in German: Schubverhalten von Biegebauteilen ohne Querkraftbewehrung].

[32] Muttoni A, Fernández Ruiz M. Shear strength of members without transverse reinforcement as function of critical shear crack width. ACI Struct J 2008;105 (2):163-72 [Farmington Hills, USA].

[33] Pérez Caldentey A, Padilla P, Muttoni A, Fernández Ruiz M. Effect of load distribution and variable depth on shear resistance of slender beams without stirrups. ACI Struct J 2012;109:595-603 [USA].

[34] Correlated solutions. Vic-3D 2010 reference manual; 2010. 108 p.

[35] Collins MP, Mitchell D, Adebar P, Vecchio F. A general shear design method. ACI Struct J 1996;93(5):36-45.

[36] Jacobsen JS, Poulsen PN, Olesen JF. Characterization of mixed mode crack opening in concrete. Mater Struct 2012;45:107-22.

[37] Campana S, Fernández Ruiz M, Anastasi A, Muttoni A. Analysis of sheartransfer actions on one-way RC members based on measured cracking pattern and failure kinematics. Mag Concr Res 2013;65(6):386-404 [UK]. 